\title{
A NOVEL DECISION-MAKING FRAMEWORK BASED ON PROBABILISTIC LINGUISTIC TERM SET FOR SELECTING SUSTAINABLE SUPPLIER CONSIDERING SOCIAL CREDIT
}

\author{
Yuanxiang $\mathrm{DONG}^{1,2}$, Xumei $\mathrm{ZHENG}^{3}$, Zeshui XU²*, \\ Weijie $\mathrm{CHEN}^{4}$, Hongbo $\mathrm{SHI}^{5}$, Ke GONG ${ }^{6}$ \\ ${ }^{1}$ School of Economics and Management, Taiyuan University of Technology, 030024 Taiyuan, China \\ ${ }^{2}$ State Key Laboratory of Hydraulics and Mountain River Engineering, Business School, \\ Sichuan University, 610064 Chengdu, China \\ ${ }^{3}$ School of Management Science and Engineering, Shanxi University of Finance and Economics, \\ 030006 Taiyuan, China \\ ${ }^{4}$ School of Economics and Management, Chongqing Normal University, 400047 Chongqing, China \\ ${ }^{5}$ College of Information, Shanxi University of Finance and Economics, 030006 Taiyuan, China \\ ${ }^{6}$ School of Economics and Management, Chongqing Jiaotong University, 400074 Chongqing, China
}

Received 26 January 2021; accepted 29 June 2021; first published online 14 September 2021

\begin{abstract}
Sustainable supplier selection (SSS) has become an essential task for decision-makers in competitive environments. We construct a new decision-making framework for SSS. First, classical SSS usually includes fixed factors in environmental, social and economic dimensions. Differently, we adopt new social factors from credit perspective with corporate social credit system being promoted vigorously by the Chinese government. Next, we employ probabilistic linguistic term sets (PLTSs) to collect experts' judgments about interactive influence between factors. Third, we combine PLTSs with Decision Making Trial and Evaluation Laboratory (DEMATEL) method to identify critical success factors (CSFs) for improving decision-making efficiency. And we also give definition to relative importance degree, standard relative importance degree, deviation of importance degree and influence degree to reflect the interactive influence between factors. To eliminate subjective influence, we combine entropy weighting approach and DEMATEL to compute weights. Fourthly, we redefine dominance degree and apply it into TODIM method for SSS. Finally, the proposed decision-making framework's effectiveness is verified by using the case study of a new energy vehicle (NEV) company. Based on this, sensitivity analysis and comparison of methods are conducted. The results verify that the decision-making framework is valid and effective for SSS.
\end{abstract}

Keywords: sustainable supplier selection, social credit, probabilistic linguistic term sets, critical success factors, DEMATEL, TODIM.

JEL Classification: C43, C61, D81, M11, Q56.

Online supplementary material: Supporting information for this paper is available as online supplementary material at https://doi.org/10.3846/tede.2021.15351

*Corresponding author. E-mail: xuzeshui@263.net

Copyright $\odot 2021$ The Author(s). Published by Vilnius Gediminas Technical University

This is an Open Access article distributed under the terms of the Creative Commons Attribution License (http://creativecommons. org/licenses/by/4.0/), which permits unrestricted use, distribution, and reproduction in any medium, provided the original author and source are credited. 


\section{Introduction}

Supplier selection is a vital step in enterprise supply chain management (SCM) (Daultani et al., 2019). In response to the growing importance of environmental and social issues, Bai and Sarkis (2010) first proposed a sustainable concept for supplier selection based on triple bottom line (TBL) theory (Elkington, 1998). Sustainable supplier selection (SSS) can reduce environmental pollution and fuel consumption (Cuthbertson et al., 2011; Kannan et al., 2020). Increasing global awareness of environmental protection and policy pressures have driven enterprises to move towards SSS (Garg et al., 2017; Parajuli et al., 2019). Thus, SSS has become a focus for researchers and business managers.

SSS have evolved from green supplier selection. Selecting green suppliers considers both economic and environmental dimensions (Ahi \& Searcy, 2013; Mi et al., 2020; Lei et al., 2020b; Wei et al., 2019; Wei et al., 2021a). The economic dimension generally includes quality, cost, distribution, and technology (Wisner et al., 2014; Haeri \& Rezaei, 2019). The environmental dimension generally includes fuel, pollution, and ecological technology (Igarashi et al., 2013; Rashidi \& Cullinane, 2019). In contrast with the economic and environmental dimensions adopted in green supplier selection, the emergence of TBL theory (Elkington, 1998) has increasingly drawn attention to the social dimension (Seuring \& Müller, 2008). Further, social dimensions have been added in recent research on SSS because social factors largely support enterprises' sustainable development (Szegedi \& Kerekes, 2012; Busse et al., 2016; Liu et al., 2019c). The social dimension usually involves worker dismissal processes and employee rights, safety, and welfare (Govindan et al., 2013; Blome et al., 2014; Luthra et al., 2017). It's worth noting that the establishment of a social credit system has become an important policy in China since 2002 (The State Council, 2017). A Chinese corporate social responsibility summit forum in 2019 also stressed that social credit has become a crucial factor for enterprises' sustainable development (Ministry of Commerce of the People's Republic of China, 2019; Song et al., 2017). This makes it necessary to consider credit when constructing comprehensive factor system to SSS.

Realistically, SSS involves significant ambiguity and fuzziness (Fallahpour et al., 2017; Lin et al., 2018a; Peng et al., 2020), because of variabilities in the external environment and preferences expressed by experts during evaluation process (Zhang et al., 2017). In recent years, the research methods of SSS based on fuzzy set and its extension theories have developed rapidly. Hoseini et al. (2020) presented a model based on Fuzzy set considering the probabilities to select the supplier with the sustainability criteria. Because intuitionistic fuzzy set has efficacy in representing uncertainty and vagueness in membership, non-membership and hesitancy values, Phochanikorn and Tan (2019) proposed the model for SSS under an intuitionistic fuzzy environment. To address strong fuzziness, ambiguity and inexactness during the evaluation process, interval-valued fuzzy sets (Foroozesh et al., 2018), interval-valued Pythagorean fuzzy sets (Yu et al., 2019), interval type-2 fuzzy sets (Alk, 2020), and interval type-2 trapezoidal fuzzy sets (Hendiani et al., 2020) were employed for SSS.

Further, as most cases of SSS involves many factors, many scholars have proposed integrated SSS models, composed of fuzzy set and classical multi-attribute decision making (MADM) methods, for instance, fuzzy TOPSIS, fuzzy VIKOR, and fuzzy PROMETHEE 
(Senvar et al., 2014; Fallahpour et al., 2017; Yu et al., 2017; Zhou \& Xu, 2018; Banaeian et al., 2018). But in fact, experts do not always precisely express their opinions in quantitative terms and tend to use linguistic information to make evaluation (Xu, 2007). As such, scholars have introduced decision-making methods based on linguistic information and extended it into SSS. Liu et al. (2019b) constructed a new integrated MCDM model for SSS under interval-valued intuitionistic uncertain linguistic environment. Liao et al. (2020) put forward a method for SSS based on hesitant fuzzy linguistic term set. As the extension of the hesitant fuzzy linguistic term set, probabilistic linguistic term set (PLTS) (Pang et al., 2016) not only contains different linguistic terms but also can express the probability information of each linguistic term. Therefore, Song and Li (2019) presented a large-scale group decision-making with incomplete multi-granular probabilistic linguistic term sets and its application in SSS.

However, three problems have emerged with respect to previous SSS models. First, these studies applied the existing factors to SSS, but didn't identify critical success factors (CSFs) (Sahu et al., 2016; Zimmer et al., 2016; Arabsheybani et al., 2018), this may lead to wasted resources and complexity in the subsequent decision-making process. Second, most MADM methods adopt subjective weights by using AHP, ANP methods (Kaur et al., 2014; Yu et al., 2019; Jabbar et al., 2019; Chen et al., 2018). This leads to the deviation of decision result from reality and increase the limitation of decision-making. Third, most decision-making methods do not consider the psychological changes of decision makers (Liu et al., 2019b; Erfan et al., 2019; Negash et al., 2020), which could lead to unpractical results.

To address the problems above, we construct a new decision-making framework including the following improvements. First, we reconstruct the factor system according to the background of Chinese vigorous credit system construction and innovatively add credit factors to select sustainable suppliers. Social factors are identified from the perspective of credit. Second, the new decision-making framework adopts PLTSs to manifest experts' preferences during the evaluation process. Assigning different probability values to linguistic terms, enabling PLTS to effectively express information compared with linguistic term set (LTS) as well as numerical expression, and increasing the precision of decision-making. Third, to simplify the decision-making process and reflect the interactive influence of factors, we combine PLTSs with DEMATEL to solve the problem of CSFs' identification in uncertain environment. At the same time, the expert's preference information on factors is reflected. We also propose the concepts of relative importance degree, standard relative importance degree, deviation of importance degree, and influence degree. These describe the interactive influence between factors. Take both subjective and objective aspects into consideration, then we combine entropy weighting approach and DEMATEL to acquire CSFs' weight. Fourth, to fully consider the psychological state of experts, we adopt TODIM, on the basis of prospect theory, as the preliminary decision-making method to make SSS. We also redefine the dominance degree based on the standard relative importance degree and comparison laws. According to the new dominance degree, we adopt TODIM method to construct new framework for making SSS. Finally, to present the proposed method's effectiveness, the proposed framework is applied in a case study involving a Chinese new energy vehicles (NEVs) company planning to make SSS. 
The rest of this article is composed as follows: Section 1 explains the SSS's factors from the perspective of economic, environmental and social credit. Section 2 introduces the mathematical preliminaries, and the proposed decision-making framework is introduced in Section 3. In Section 4, we adopt a case study to verify the proposed method's effectiveness, focusing on making SSS in a Chinese NEV company. Section 5 presents discussions about the new framework. The last Section concludes.

\section{Sustainable supplier selection factors}

Establishing a suitable SSS factor system can be seen as an essential step to get the optimal supplier. Previous studies about supplier selection mainly payed attention to the economic and environmental these two dimensions (Ahi \& Searcy, 2013; Graham et al., 2015). The occurrence of triple bottom line (TBL) theory indicates the beginning of SSS development. TBL theory includes economic, environmental, and social dimensions, among which the social dimension received the most attention until recent years (Bai \& Sarkis, 2010; Zimmer et al., 2016). Gradually, more researchers agree that the factors for SSS should focus on three dimensions comprehensively: economic, environmental, and social (Seuring \& Müller, 2008; Fallahpour et al., 2017; Gören, 2018; Yu et al., 2019). The existing studies emphasized that enterprises should engage in social responsibility to achieve sustainable development (Szegedi \& Kerekes, 2012). China has widely focused on constructing credit system and promulgating credit policies to promote the sustainable development of enterprises (The State Council, 2021). The level of sustainable development in enterprises is evaluated by considering environmental implementation, tax implementation, and quality implementation. However, the existed factors have not been able to fully tally the enterprises' implementation capacity, making it less effective for SSS.

We establish a new factor system, which adopts several social factors from the perspective of credit innovatively. According to previous studies, economic and environmental factors are reorganized and details can be seen in Table 1. Innovative social factors are extracted from relevant policies, which are shown in Table 2. Table 1 and Table 2 are followed by a more detailed explanation of factors, which is shown in Table 3.

\subsection{Economic}

$\kappa_{1}$ : Technology capability. Wilson et al. (1994) considered technology capability to be popular economic factor. Chen (2011) noted that technology can play an essential role during SSS, as technology will drive economic development to realize sustainable economic development.

$\kappa_{2}$ : Confidence in a durable product. A successful sustainable product service system should take sustainability into account to extend the product lifecycle (Khan et al., 2018). Liu et al. (2019a) posited that durable products enable society to establish a new ecosystem of sustainable development. This requires the supplier to provide products of reliable quality and a long life cycle.

$\kappa_{3}$ : Price of products. Weber et al. (1991) reviewed literature for assessing the criterion most frequently used to select suppliers. From the perspective of sustainable development, product 
price is an important factor (Khoshfetrat et al., 2020). Reasonable prices can meet the needs of most consumers, and can attract and retain consumers to achieve sustainable development. $\kappa_{4}$ : Financial capability. The financial stability of suppliers directly affects sustainability (Amindoust et al., 2012). It is the underlying premise and guarantee that supports all other activities. Girubha et al. (2016) focused on financial capability as a factor in studying SSS. Financial capability status is critical in evaluating suppliers.

$\kappa_{5}$ : Increase in supply flexibility. Chaharsooghi and Ashrafi (2014) addressed supply flexibility, which has a great influence on economic development. Organizations benefit from increasing their supply flexibilities to respond to manufacturing schedule fluctuations, demand volatility, and forecast accuracy (Li et al., 2019).

\subsection{Environmental}

$\kappa_{6}$ : Energy usage. Energy usage is linked to achieving supplier environmental goals (Neumüller et al., 2016). To increase the utilization rate of new energy and to alleviate pollution problems, the Chinese government proposed a range of policies related to new energy development (Lin et al., 2018b). The rational use of energy can reduce pollution and realize the long-term development of suppliers.

$\kappa_{7}$ : Pollution reduction. Pollution reduction is a fundamental factor in an enterprise to meet ecological standards (Jia et al., 2015; Hou et al., 2020). Memari et al. (2019) considered how the pollution reduction criterion related to reducing the amount of supplier's greenhouse gas emissions to align them with regional and international ecological policies.

$\kappa_{8}$ : Environmental skill. Environmental skill can be an effective way to attain green production, increasing environmental performance (Fallahpour et al., 2017). Because environmental technology allows suppliers to reduce pollutant emissions, Liu et al. (2019a) considered environmental skills in SSS.

Table 1. Criteria of economic and environmental aspects

\begin{tabular}{|c|c|c|c|c|}
\hline Perspective & Sub-Criterion & Application & Journal & Author \\
\hline Economic & $\begin{array}{l}\text { Technology capability } \\
\text { Confidence in a } \\
\text { durable product } \\
\text { Price of products } \\
\text { Financial capability } \\
\text { Increase of supply } \\
\text { flexibility }\end{array}$ & $\begin{array}{l}\text { Supplier selection } \\
\text { NEVs } \\
\text { Automotive industry } \\
\text { Supplier selection } \\
\text { Supply chain } \\
\text { management }\end{array}$ & $\begin{array}{l}\text { Information Science } \\
\text { Journal of Cleaner } \\
\text { Production } \\
\text { Engineering } \\
\text { Optimization } \\
\text { Applied Soft Computing } \\
\text { Journal of Cleaner } \\
\text { Production }\end{array}$ & $\begin{array}{l}\text { Chen et al. } \\
\text { Liu et al. } \\
\text { Sahar et al. } \\
\text { Amindoust } \\
\text { et al. } \\
\text { Li et al. }\end{array}$ \\
\hline $\begin{array}{l}\text { Environ- } \\
\text { mental }\end{array}$ & $\begin{array}{l}\text { Energy usage } \\
\text { Pollution reduction } \\
\text { Environmental skill } \\
\text { Eco-design } \\
\text { Environmental } \\
\text { awareness }\end{array}$ & $\begin{array}{l}\text { Energy power system } \\
\text { Automotive spare } \\
\text { parts } \\
\text { Watch manufacturer } \\
\text { Selection } \\
\text { Supplier selection } \\
\text { Photo-voltaic module } \\
\text { Supplier selection }\end{array}$ & $\begin{array}{l}\text { Journal of Cleaner } \\
\text { Production } \\
\text { Journal of Manufacturing } \\
\text { Systems } \\
\text { Information Sciences } \\
\text { Expert Systems With } \\
\text { Applications } \\
\text { Energy }\end{array}$ & $\begin{array}{l}\text { Lin et al. } \\
\text { Ashkan } \\
\text { et al. } \\
\text { Liu et al. } \\
\text { Yu et al. } \\
\text { Wu et al. }\end{array}$ \\
\hline
\end{tabular}


Table 2. Factors of credit aspect

\begin{tabular}{|c|c|c|c|c|}
\hline Perspective & Sub-Criterion & Application & Policy & organization \\
\hline \multirow[t]{5}{*}{ Credit } & $\begin{array}{l}\text { Administrative reward and } \\
\text { penalties }\end{array}$ & \multirow{5}{*}{$\begin{array}{l}\text { Regulate } \\
\text { business } \\
\text { to ensure } \\
\text { sustainable } \\
\text { development }\end{array}$} & $\begin{array}{l}\text { Enterprise integrity } \\
\text { management system }\end{array}$ & SAC \\
\hline & $\begin{array}{l}\text { Quality commitment } \\
\text { performance }\end{array}$ & & $\begin{array}{l}\text { Environmental protection } \\
\text { enterprise credit evaluation } \\
\text { index system }\end{array}$ & CAEPI \\
\hline & Contract Compliance & & $\begin{array}{l}\text { Sustainability for } \\
\text { manufacturing } \\
\text { organizations }\end{array}$ & US-UL \\
\hline & $\begin{array}{l}\text { Enterprise overall } \\
\text { management quality credit }\end{array}$ & & $\begin{array}{l}\text { Index of enterprise credit } \\
\text { evaluation }\end{array}$ & SAC \\
\hline & Tax-paying credit level & & $\begin{array}{l}\text { Outline of the plan for the } \\
\text { construction of the social } \\
\text { credit system (2014-2020) }\end{array}$ & $\begin{array}{l}\text { The State } \\
\text { Council }\end{array}$ \\
\hline
\end{tabular}

Table 3. Specific interpretation of factors

\begin{tabular}{|c|c|}
\hline Criterion/factors & Explanations \\
\hline \multicolumn{2}{|r|}{ Economic (A1) } \\
\hline Technology capability $\left(\kappa_{1}\right)$ & $\begin{array}{l}\text { Suppliers' ability to make products that are up-to-date and meet } \\
\text { customers' needs }\end{array}$ \\
\hline $\begin{array}{l}\text { Confidence in a durable } \\
\text { product }\left(\kappa_{2}\right)\end{array}$ & Supplier tolerance with respect to the products offered \\
\hline Price of product $\left(\kappa_{3}\right)$ & The lowest market price that the purchaser can afford \\
\hline Financial capability $\left(\kappa_{4}\right)$ & $\begin{array}{l}\text { The suppliers' maintenance of adequate funds to support } \\
\text { enterprise operations }\end{array}$ \\
\hline Increase in supply flexibility $\left(\kappa_{5}\right)$ & Different schemes available to satisfy customers' needs \\
\hline \multicolumn{2}{|r|}{ Environmental (A2) } \\
\hline Energy usage $\left(\kappa_{6}\right)$ & $\begin{array}{l}\text { Use of green energy to ensure environmental benefits for } \\
\text { sustainable development }\end{array}$ \\
\hline Pollution reduction $\left(\kappa_{7}\right)$ & $\begin{array}{l}\text { The reduction of pollutants that are emitted into natural } \\
\text { environment }\end{array}$ \\
\hline Environmental skill $\left(\kappa_{8}\right)$ & The ability to ensure that the enterprise is pollution-free \\
\hline Eco-design $\left(\kappa_{9}\right)$ & $\begin{array}{l}\text { Products designed to protect the environment throughout the } \\
\text { life cycle }\end{array}$ \\
\hline Environmental awareness $\left(\kappa_{10}\right)$ & $\begin{array}{l}\text { Awareness of protecting the environment by taking a series of } \\
\text { activities }\end{array}$ \\
\hline \multicolumn{2}{|r|}{ Credit (A3) } \\
\hline $\begin{array}{l}\text { Administrative reward and } \\
\text { punishment }\left(\kappa_{11}\right)\end{array}$ & Abide by the national credit law to fulfill legal obligations \\
\hline $\begin{array}{l}\text { Quality commitment } \\
\text { performance }\left(\kappa_{12}\right)\end{array}$ & Equivalent products provided to consumers to win trust \\
\hline Contract compliance $\left(\kappa_{13}\right)$ & $\begin{array}{l}\text { Establish product quality management standards to ensure } \\
\text { compliance with enterprise's specifications }\end{array}$ \\
\hline $\begin{array}{l}\text { Enterprise overall management } \\
\text { quality credit }\left(\kappa_{14}\right)\end{array}$ & $\begin{array}{l}\text { Fulfill commitments to meet employees' psychological and } \\
\text { physical needs }\end{array}$ \\
\hline Tax-paying credit level $\left(\kappa_{15}\right)$ & Pay taxes on time to meet expectations for social responsibility \\
\hline
\end{tabular}


$\kappa_{9}$ : Eco-design. Wittstruck and Teuteberg (2012) noted that suppliers may provide products with a green image, that is, products designed to be eco-friendly. When the goal is sustainability, designing products with a consideration of the environment makes sense during the whole product lifecycle (Yu et al., 2019).

$\kappa_{10}$ : Environmental awareness. To better demonstrate corporate environmental responsibility, decision-makers would rather to choose sustainable suppliers that performs better in reducing pollution (Wu et al., 2019). More practitioners and researchers have focused on sustainable supply chain management to increase environmental awareness (Boudaghi \& Farzipoor Saen, 2018). This indicates that environmental awareness is becoming a major concern of experts.

\subsection{Credit}

As modernization has proceeded, the Chinese government has increased its attention to constructing a social credit system. National policies and programs include sustainable corporate development goals. The enterprise integrity management system (National Standardization Administration of China [SAC], 2015b) highlights administrative rewards and penalties through enterprise credits. The environmental protection enterprise credit evaluation index system (China Environmental Protection Industry Association [CAEPI], 2018) emphasizes the realization of a commitment to quality credits, to produce commodities that meet needs. Social responsibility is a basic factor measuring the enterprise's credit and clearly reporting whether the enterprise operates in a sustainable way (Underwriters Laboratories [US-UL], 2011). Contract compliance is a good proxy for responsibility. The index of enterprise credit evaluation (SAC, 2015a) also reflects whether an enterprise's overall management quality credit is strongly related with the establishment of social credit. The outline of the plan for constructing the social credit system (2014-2020) (The State Council, 2014) also clearly states that enterprises should pay taxes according to law. The tax-paying credit level affects the subsequent sustainable development of enterprises. Relevant policies are analyzed and five social factors are sorted out, they are summarized as follows:

$\kappa_{11}$ : Administrative reward and penalties (SAC, 2015b);

$\kappa_{12}$ : Quality commitment performance (CAEPI, 2018);

$\kappa_{13}$ : Contract compliance (US-UL, 2011);

$\kappa_{14}$ : Enterprise overall management quality credit (SAC, 2015a);

$\kappa_{15}$ : Tax-paying credit level (State Council, 2014).

\section{Preliminaries}

Pang et al. (2016) first put forward the probabilistic linguistic term sets (PLTSs), composed of probable linguistic terms as well as equivalent probabilistic values. As an extension of hesitant fuzzy linguistic term sets (HFLTs) (Rodriguez et al., 2011), PLTSs considers different weight of possible linguistic term set (LTS) to generate more reasonable results (Gou \& Xu, 2016; Wang et al., 2021; Lei et al., 2020a). 
Definition 1 (Pang et al., 2016). Let $S_{2}=\left\{s_{0}, s_{1}, \ldots, s_{\tau}\right\}$ be a LTS with asymmetric subscripts. And PLTS can be expressed in the form of mathematics as follows:

$$
L(p)=\left\{L^{(k)}\left(p^{(k)}\right) \mid L^{(k)} \in S_{2}, p^{(k)} \geq 0, k=1,2, \ldots, \# L(p), \sum_{k=1}^{\# L(p)} p^{(k)} \leq 1\right\},
$$

where the element $\left.L^{(k)} p^{(k)}\right)$ is composed of the $k$-th linguistic term $L^{(k)}$ and its probability $p^{(k)}$ and the term $\# L(p)$ denotes the number of elements in $L(p)$. The linguistic terms $L^{(k)}$, $k=1,2, \ldots, \# L(p)$ in $L(p)$ are arranged in ascending order.

From Definition 1, $\sum_{k=1}^{\# L(p)} p^{(k)} \leq 1$ means that the sum of probabilities in a PLTS is less than 1. This implies that experts only evaluate partial objects. We use the probability aggregation method (Pang et al., 2016) to integrate the experts' opinions, which are expressed as the LTS. Then, we transform the evaluation of LTS into PLTSs collectively. Example 1 shows this conversion.

Example 1. A hundred consumers are invited to express how they feel about the overall comfortable degree of a sofa. Suppose that sixty-five consumers state that it is high, twenty consumers state that it is very high, ten consumers insist that it is slightly high, and others do not express any opinions. In this case, the obtained information can be summarized as follows: Comfort $=\{$ slightly high $(0.1)$, high (0.65), very high (0.2) $\}$. Suppose that LTS can be indicated as: $S=\left\{S_{0}=\right.$ very low, $S_{1}=$ low, $S_{2}=$ slightly low, $S_{3}=$ fair, $S_{4}=$ slightly high, $S_{5}=$ high, $S_{6}=$ very high $\}$, then the PLTS can be denoted as $L(p)=\left\{S_{4}(0.1), S_{5}(0.65), S_{6}(0.2)\right\}$.

The expressions $L_{1}(p)=\left\{L_{1}{ }^{(k)} p_{1}{ }^{(k)} \mid k=1,2, \ldots, \# L_{1}(p)\right\}$ and $L_{2}(p)=\left\{L_{2}{ }^{(k)} p_{2}{ }^{(k)} \mid k=1,2, \ldots\right.$, $\left.L_{2}(p)\right\}$ are two PLTSs. Having different numbers of linguistic terms in PLTSs places the subsequent calculation in conflict. As such, Pang et al. (2016) proposed the following method to extend the terms to have the same number of elements. If \# $L_{1}(p)>\# L_{2}(p)$, then $\# L_{1}(p)-\# L_{2}(p)$ linguistic terms are added into $L_{2}(p)$ making the numbers of elements in the two PLTSs equal. The added linguistic terms have the smallest subscript in, and the probabilities of added linguistic terms are zero (Lin et al., 2018a). This yields the normalized PLTSs (NPLTSs).

Definition 2 (Zhang et al., 2019). Suppose $L(p)$ be a PLTS on the linguistic evaluation scale $S=\left\{s_{\alpha} \mid \alpha=-\tau, \ldots,-1,0,1, \ldots \tau\right\}$, and $L(p)^{N}$ be the equivalent NPLTSs. The measurement of $L(p)$ can be calculated by:

$$
S^{\zeta}(L(p))=S^{\zeta}\left(L(p)^{N}\right)=\left(\left(\gamma^{N(1)} p^{N(1)}\right)^{\zeta}+\left(\gamma^{N(2)} p^{N(2)}\right)^{\zeta}+\ldots+\left(\gamma^{N\left(\# L(p)^{N}\right)} p^{N\left(\# L(p)^{N}\right)}\right)^{\zeta}\right)^{\frac{1}{\zeta}},
$$

where the $l$-th linguistic term's $\left(L^{N(\mathrm{l})}\right)$ subscript in $L(p)^{N}$ is $\gamma^{N(\mathrm{l})}$; and $\zeta(0 \leq \zeta \leq 1)$ is a parameter given by the decision maker in a specific case.

Definition 3 (Zhang et al., 2019). For any two PLTSs $L(p)_{1}$ and $L(p)_{2}$, comparison laws are defined as:

$$
\begin{aligned}
& \text { 1. If } S^{\zeta}\left(L(p)_{1}\right)>S^{\zeta}\left(L(p)_{2}\right) \text {, then } L(p)_{1} \succ L(p)_{2} \text {; } \\
& \text { 2. If } S^{\zeta}\left(L(p)_{1}\right)=S^{\zeta}\left(L(p)_{2}\right) \text {, then } L(p)_{1} \sim L(p)_{2} \text {; } \\
& \text { 3. If } S^{\zeta}\left(L(p)_{1}\right)<S^{\zeta}\left(L(p)_{2}\right) \text {, then } L(p)_{1} \prec L(p)_{2} \text {. }
\end{aligned}
$$




\section{A novel decision-making framework}

To construct the novel decision-making framework, we combine PLTSs and DEMATEL methods and then propose relative importance degree, standard relative importance degree, deviation of importance degree and influence degree for identifying CSFs. To avoid making decisions subjective, we integrate entropy weighting approach and DEMATEL to calculate weights. Considering the psychological changes of experts, we redefine the dominance degree based on standard relative importance degree and comparison laws to combine the TODIM and DEMATEL method in this framework. The decision-making framework is as Figure 1 shows.

\subsection{Assessment of importance and influence degree in PLTSs}

The existing score function of PLTSs is used to rank and measure, it cannot reflect the interaction between factors. Therefore, according to score function and degree of deviation (Pang et al., 2016), we further propose the relative importance degree, standard relative importance degree, deviation of importance degree and influence degree of PLTS to combine PLTSs and DEMATEL.

Definition 4. Let $\left.L(p)=\left\{l^{(k)}\left(p^{(k)}\right)\right\} \mid k=1,2, \ldots, \# L(p)\right\}$ be a PLTS; $r^{(k)}$ is the $k$-th PLTS's subscript; $p^{(k)}$ stands for the probability of the $k$-th linguistic term $(k=1,2, \ldots, \# l(p)) ; \# l(p)$ is the amount of linguistic terms of $L(p)$. Thus, the relative importance degree of $L(p)$ is calculated as:

$$
I(L(p))=\left(\sum_{k=1}^{\# l(p)} r^{(k)} p^{(k)}\right)(\# l(p))^{-1}, k=1,2, \ldots, \# l(p) .
$$

Definition 5. Given a PLTS $L(p)$, the standard relative importance degree of $L(p)$ can be calculated by:

$$
S I(L(p))=\left(\sum_{k=1}^{\# l(p)}\left(r^{(k)}\right)\left(p^{(k)}\right)^{3}\right)^{\frac{1}{2}}(\# l(p))^{-\frac{3}{2}} \text {. }
$$

Definition 6. $S I$ is the standard relative importance degree of $L(p)$ in the standard relative importance matrix $\left[S I_{i j}\right]_{n \times n}(i, j=1,2, \ldots, n)$. We define the deviation in the importance degree as:

$$
\tilde{\rho}=S I^{+}-S I^{-},
$$

where $S I^{+}=\operatorname{Max}_{i}\left(\max _{j}\left[S I_{i j}\right]\right)(i, j=1,2, \ldots, n)$ denotes a superior standard relative importance degree, and $S I^{-}=\operatorname{Min}_{i}\left(\max _{j}\left[S I_{i j}\right]\right)(i, j=1,2, \ldots, n)$ denotes an inferior standard relative impor-
tance degree.

Definition 7. $\tilde{\rho}$ is the deviation in the importance degree, based on the standard relative importance matrix $\left[S I_{i j}\right]_{n \times n}(i, j=1,2, \ldots, n)$. The influence degree of $L(p)$ can be calculated by the following function:

$$
\S(L(p))=\frac{\sqrt{\sum_{k=1}^{\# l(p)}\left(p^{(k)}\right)^{2}\left(r^{(k)} p^{(k)}-\tilde{\rho}\right)^{2}}}{(\# l(p))^{2}}, k=1,2, \ldots, \# l(p) .
$$




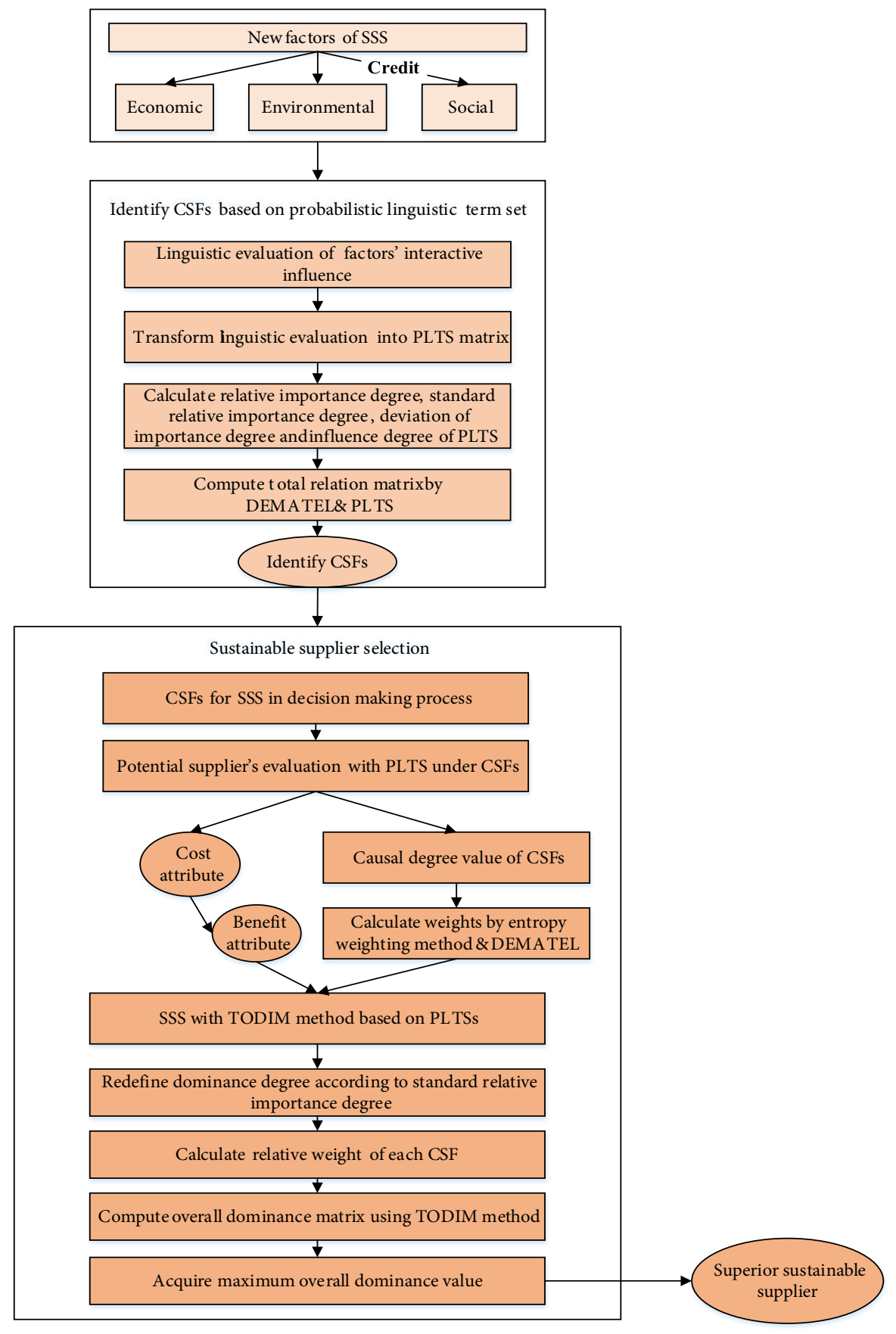

Figure 1 . The decision-making framework of this paper 


\subsection{Identifying CSFs}

Having different occurrence probabilities of all possible linguistic terms, PLTSs reflect experts' preference rationally (Gao et al., 2019). Thus PLTS DEMATEL method reveals the interaction relationship among different factors (Hu et al., 2021; Xu \& Wang, 2017). In line with identification of CSFs, this decision-making framework adopts the DEMATEL method on the basis of PLTSs. And the specific steps are shown as follows:

Step 1. Making initial linguistic evaluation on interaction relationship between factors. Adopt $\kappa_{i}$ to represent the factors of SSS introduced in Section 1. Establish a linguistic term scale (Table 4) for SSS factors' pair-wise comparisons for experts, which is consistent with the desired purpose of evaluating the interaction between factors. Different linguistic terms in the linguistic scale $\left\{S_{0}, S_{1}, S_{2}, S_{3}, S_{4}\right\}$ refers to different degree of direct influence between any two factors, they stand for "no", "very low", "low", "high" and "very high" to assess the influence in turn. Develop a questionnaire and then collect the experts' opinions. Then we generate the initial linguistic evaluation matrix.

Table 4. Linguistic term scale for sustainable supplier selection factors' pair-wise comparisons

\begin{tabular}{|c|c|}
\hline Linguistic term & Linguistic variables \\
\hline$S_{0}$ & no \\
\hline$S_{1}$ & very low \\
\hline$S_{2}$ & low \\
\hline$S_{3}$ & high \\
\hline$S_{4}$ & very high \\
\hline
\end{tabular}

Step 2. Calculating the relative importance matrix. Based on the probability aggregation method in Definition 1, convert experts' linguistic assessments into corresponding PLTSs. To force PLTSs to have same number of linguistic terms, PLTSs are transformed into NPLTSs. Based on the NPLTSs, the relative importance matrix is generated using Eq. (4).

Step 3. Obtaining the standard relative importance matrix. Using Eq. (5), generate the standard relative importance matrix.

Step 4. Generating the initial direct matrix. According to standard relative importance matrix, generate an initial direct relation matrix of DEMATEL method, by using the deviation on the importance degree (Eq. (6)) and the influence degree function (Eq. (7)). The initial direct relation matrix shows the influential relationship between factors. The character Mij represents the degree that the factor $i$-th affects the factor $j$-th in $n \times n$ non-negative matrix $M$.

Step 5. Normalizing initial direct relation matrix. Calculate the normalized initial direct relation matrix as:

$$
U=\frac{M}{\max _{i=1}^{n}\left\{\sum_{j=1}^{n} m_{i j}\right\}} .
$$


Step 6. Constructing the total relation matrix. Compute the total relation matrix $T$ using Eq. (9). $I$ is the $n \times n$ unit matrices; and $U$ represents the normalized initial direct relation matrix. According to the matrix inversion (Wu \& Chang, 2015), the total relation matrix $T$ can be denoted as follows:

where $T=\left[t_{i j}\right]_{n \times n}(i, j=1,2, \ldots, n)$.

$$
T=U(I-U)^{-1},
$$

Step 7. Identifying CSFs. Calculate the sums of each row $i$ and column $j$ of $T$ :

$$
R_{i}=\sum_{i=1}^{n} t_{i j}, j=1,2, \ldots, n .
$$

After completing the calculation above, the sum of $i$-th rows $R_{i}(i=1,2, \ldots, n)$ shows both direct and indirect effects, given by $i$-th factor to the other factors.

$$
C_{j}=\sum_{j=1}^{n} t_{j i}, i=1,2, \ldots n .
$$

The sum of the $j$-th columns $C_{j}(j=1,2, \ldots, n)$ regarding matrix $T$ indicates both direct and indirect effects by the $j$-th factor from the other factors.

According to above $R_{i}$ and $C_{j}$, compute the overall prominence $P_{i}$ and the causal degree $E_{i}$ in the DEMATEL method using Eq. (12) and Eq. (13).

$$
P_{i}=\left\{R_{i}+C_{j}, i=j\right\} \text {. }
$$

The larger $P_{i}$ is, the better the overall dominance of the $i$-th factor with respect to its overall relationship with other factors is.

$$
E_{i}=\left\{R_{i}-C_{j}, i=j\right\} .
$$

As for the causal degree, the $i$-th factor is a net effect of other factors if $E_{i}<0$. Factors with a negative $E_{i}$ value are in the effect group. Otherwise, if $E_{i}>0$, then the $i$-th factor is a net cause (Tzeng et al., 2007). CSFs are the factors with positive values of $E_{i}$, and they affect other factors. Thus, we use $\kappa_{\lambda}^{\prime}(\lambda=1,2, \ldots, s ; 1 \leq s \leq n)$ to represent the identified CSFs by using DEMATEL method.

\subsection{Entropy weighting approach with DEMATEL method}

Entropy weighting approach is an objective weighting method. It calculates entropy value of CSF, and then determines the weight of the CSF according to the influence of each CSF on the whole system. As a method widely used in various fields, it eliminates the subjectivity of other weight determination methods, such as AHP, ANP, DEMATEL method. For ensuring the authenticity and validity of our decision-making framework, entropy weighting method is adopted based on the determination of CSFs' casual degree, which is obtained by DEMATEL method. The specific steps for calculating weights can be summarized as follows:

Step 1. Normalize initial data. The casual degree value of CSFs in total influence matrix, obtained from DEMATEL method, is taken as the initial value. And $E_{i}>0$, so we need to calculate the proportion of $j$-th CSF in CSFs' system for revealing the variation degree of this CSF. 


$$
V_{\mathrm{ij}}=\frac{E_{i}}{\sum_{i=1}^{n} E_{i}}
$$

Step 2. Calculate entropy value of each CSF based on normalized initial data from DEMATEL method.

where $\Lambda=\frac{1}{\ln n}$, and $e_{j}$ is $[0,1]$.

$$
e_{j}=-\Lambda \sum_{i=1}^{6} V_{\mathrm{ij}} \ln \left(V_{\mathrm{ij}}\right),
$$

Step 3. Compute the weight of $\lambda$-th CSF.

$$
W_{\lambda}=\frac{1-e_{j}}{n-\sum_{j=1}^{n} e_{j}}(\lambda=1,2, \ldots s, 1 \leq s \leq n) .
$$

\subsection{SSS with TODIM method based on PLTSs}

To fully consider the psychological state of experts, we adopt TODIM method based on prospect theory to make SSS in decision-making framework. During the process, we redefine the dominance degree in TODIM based on standard relative importance degree (Definition 5) as well as comparison laws (Zhang et al., 2019).

Definition 8. Accsording to the classical TODIM method, we propose a new rule to measure the dominance degree of the $x$-th supplier $\pi_{x}$ to the $y$-th supplier $\pi_{y}$. Considering the identified CSFs $\kappa_{\lambda}^{\prime}(\lambda=1,2, \ldots, s ; 1 \leq s \leq n)$, it is defined by:

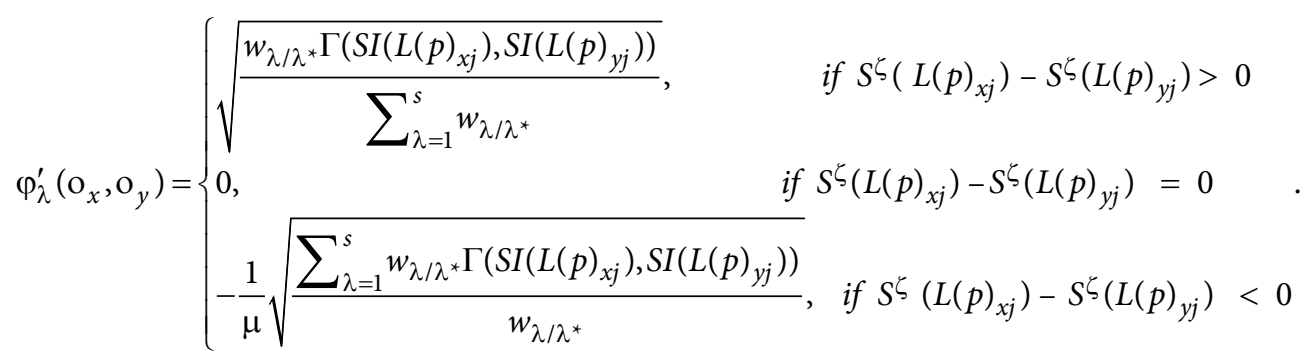

The expression $w_{\lambda / \lambda^{*}}=\frac{w_{\lambda}}{\max w_{\lambda}}(\lambda=1,2, \ldots, s ; 1 \leq s \leq n)$ represents the relative weight of $\kappa_{\lambda}^{\prime}$. Parameter $\mu(\mu>0)$ is the attenuation factor of the loss, which is inversely proportional to the degree of loss aversion. According to Definition 5, $\Gamma\left(S I\left(L(p)_{x j}\right), S I\left(L(p)_{y j}\right)\right)$ is the difference in the standard relative importance between two PLTSs. It equals $\Gamma\left(S I\left(L(p)_{x j}\right), S I\left(L(p)_{y j}\right)\right)=$ $\left|S I\left(L(p)_{x j}\right)-S I\left(L(p)_{y j}\right)\right|$.

According to the new definition above, the following steps are applied into SSS based on TODIM method: 
Step 1. Collect expert evaluations and convert them into an initial matrix of probabilistic linguistic terms $D=\left(L(p)_{i j}\right)_{m \times n}$, based on the probabilistic linguistic evaluation scale (Table 5). Experts are invited to complete questionnaires for reporting their judgments about potential suppliers.

Table 5. Linguistic term scale for sustainable supplier selection

\begin{tabular}{|c|c|}
\hline Linguistic evaluation scale & Linguistic variables \\
\hline$S_{-3}$ & pretty bad \\
\hline$S_{-2}$ & bad \\
\hline$S_{-1}$ & a little bad \\
\hline$S_{0}$ & middle \\
\hline$S_{1}$ & a little good \\
\hline$S_{2}$ & good \\
\hline$S_{3}$ & pretty good \\
\hline
\end{tabular}

Step 2. According to $\mathrm{Xu}$ (2012), normalize the initial probabilistic linguistic terms matrix $D=\left(L(p)_{i j}\right)_{m \times n}$ and transform the cost attributes into benefit attributes.

Step 3. Determine the relative weights of CSFs. Apply Eq. (16) to calculate the weights of the CSFs. Then, factor with the largest weight can be selected as the reference factor (marked as $\max w_{\lambda}$ ) and compute the relative weight of $\kappa_{\lambda}^{\prime}$ :

$$
w_{\lambda / \lambda^{*}}=\frac{w_{\lambda}}{\max w_{\lambda}}(\lambda=1,2, \ldots, s ; 1 \leq s \leq n) .
$$

Step 4. Determine the dominance matrix $\varphi_{\lambda}^{\prime}\left(\pi_{x}, \pi_{y}\right)$, and compare one supplier against another supplier under each CSF by Eq. (17).

Step 5. Calculate the overall dominance degree $\varphi^{\prime}\left(\pi_{x}, \pi_{y}\right)$ for the supplier $\pi_{x}$ to the supplier $\pi_{y}$ by using Eq. (18). The overall dominance degree is calculated as:

$$
\varphi^{\prime}\left(\pi_{x}, \pi_{y}\right)=\sum_{\lambda=1}^{s} \varphi_{\lambda}^{\prime}\left(\pi_{x}, \pi_{y}\right) .
$$

Step 6. Generate the overall values $\Phi^{\prime}\left(\pi_{x}\right)(x=1,2, \ldots, n)$ in the $i$-th row and rank the whole values to get the most sustainable supplier. The overall values of the supplier $\pi_{x}$ are:

where $0 \leq \Phi^{\prime}\left(\pi_{x}\right) \leq 1$.

$$
\Phi^{\prime}\left(\pi_{x}\right)=\frac{\sum_{y=1}^{m} \varphi^{\prime}\left(\pi_{x}, \pi_{y}\right)-\min _{i}\left\{\sum_{y=1}^{m} \varphi^{\prime}\left(\pi_{x}, \pi_{y}\right)\right\}}{\max _{i}\left\{\sum_{y=1}^{m} \varphi^{\prime}\left(\pi_{x}, \pi_{y}\right)\right\}-\min _{i}\left\{\sum_{y=1}^{m} \varphi^{\prime}\left(\pi_{x}, \pi_{y}\right)\right\}},
$$

\section{Case study}

For verifying the usefulness of the proposed decision-making framework, a case study of NEVs is provided in this section. 


\subsection{Background information about the case}

Fuel consumption in the auto industry is a concern, because it accounts for nearly $40 \%$ of Chinese total fuel consumption (Zhang \& Bai, 2017). Chinese import volumes of net crude oil exceeded 500 million tons for the first time in 2019 (General Administration of Customs of the People's Republic of China, 2019). At the same time, high levels of vehicle fuel consumption can lead to frequent smoggy weather; studies also show that exhaust fumes of motor vehicles are a main source of particulate matter in Beijing, Shanghai, and other large cities in China (Wang et al., 2014). NEVs effectively alleviate air pollution and energy shortages (The State Council, 2012; Wei et al., 2021b). Hence, the Chinese government has introduced several policies to promote the sustainable development of NEVs (Liu et al., 2018). The traditional automobile enterprises Mercedes-Benz, Volkswagen, and Honda have accelerated the layout of NEVs worldwide. Given these circumstances, selecting a high-performing sustainable supplier will enhance the sustainable development level of the automotive industry (Chinese State Council, 2014). As such, we choose this setting as our case study.

The case study focuses on providing the Chinese NEV company with a method for SSS for further development. Three stages are applied to construct a novel decision-making framework for selecting sustainable suppliers. First, DEMATEL method is combined with PLTSs to identify CSFs. Second, we combine entropy weighting approach and DEMATEL to determine CSFs' weights. Third, we adopt the TODIM method to choose the best sustainable NEVs supplier in the framework. In order to do a quantitative study, we invite 5 professional experts in the fields of NEV management. And the experts' background information is presented in Table 6 .

Table 6. Background information of experts

\begin{tabular}{|c|c|c|l|l|l|l|}
\hline Experts & Age & Service tenure & Gender & $\begin{array}{c}\text { Educational } \\
\text { background }\end{array}$ & $\begin{array}{c}\text { Occupational } \\
\text { background }\end{array}$ & Job title \\
\hline Ex1 & 46 & $>15$ & Male & Master & Governmental & Research director \\
\hline Ex2 & 50 & $>23$ & Female & Bachelor & Industrial & Financial controller \\
\hline Ex3 & 39 & $>21$ & Male & Master & Industrial & Chief technology officer \\
\hline Ex4 & 45 & $>18$ & Male & Master & Industrial & Legal specialist \\
\hline Ex5 & 42 & $>13$ & Female & Doctoral & Academic & Associate professor \\
\hline
\end{tabular}

\subsection{Calculation process of DEMATEL method based on PLTSs}

This part completes a numerical example for identifying CSFs and determining their weights in the decision-making framework, by applying DEMATEL method under PLTSs to the case study in NEV Company. The calculation process is listed as follows.

Step 1. Develop initial linguistic evaluation matrix to determine interaction between factors. We use questionnaires (in Supplementary information) to collect 5 experts' evaluation on interactive influence between factors. Using the established linguistic term scale for sustainable supplier selection factors' pair-wise comparisons (Table 4), we generate initial evaluation matrix of PLTSs (Supplementary information Table S3). 
Step 2. Construct the relative importance matrix (Table 7). The initial linguistic evaluation matrix is transformed into a PLTS form (Supplementary information Table S4). Then we use a normalization calculation (Pang et al., 2016) to produce NPLTSs (Supplementary information Table S5). Using Eq. (4), we generate a relative importance matrix based on the NPLTSs.

Table 7. Matrix of the relative importance relationships

\begin{tabular}{|c|c|c|c|c|c|c|c|c|c|c|c|c|c|c|c|}
\hline No. & $k_{1}$ & $k_{2}$ & $k_{3}$ & $k_{4}$ & $k_{5}$ & $k_{6}$ & $k_{7}$ & $k_{8}$ & $k_{9}$ & $k_{10}$ & $k_{11}$ & $k_{12}$ & $k_{13}$ & $k_{14}$ & $k_{15}$ \\
\hline$k_{1}$ & 0.00 & 0.48 & 0.35 & 0.64 & 0.32 & 0.56 & 0.44 & 0.60 & 0.32 & 0.12 & 0.52 & 0.40 & 0.24 & 0.12 & 0.40 \\
\hline$k_{2}$ & 0.24 & 0.00 & 0.36 & 0.25 & 0.32 & 0.20 & 0.44 & 0.20 & 0.32 & 0.32 & 0.24 & 0.20 & 0.40 & 0.24 & 0.56 \\
\hline$k_{3}$ & 0.16 & 0.40 & 0.00 & 0.36 & 0.52 & 0.36 & 0.25 & 0.16 & 0.52 & 0.24 & 0.16 & 0.24 & 0.24 & 0.12 & 0.32 \\
\hline$k_{4}$ & 0.60 & 0.56 & 0.32 & 0.00 & 0.48 & 0.64 & 0.40 & 0.44 & 0.48 & 0.64 & 0.60 & 0.36 & 0.28 & 0.32 & 0.64 \\
\hline$k_{5}$ & 0.24 & 0.50 & 0.52 & 0.52 & 0.00 & 0.36 & 0.36 & 0.24 & 0.16 & 0.24 & 0.24 & 0.24 & 0.20 & 0.16 & 0.16 \\
\hline$k_{6}$ & 0.48 & 0.12 & 0.24 & 0.24 & 0.16 & 0.00 & 0.44 & 0.64 & 0.16 & 0.60 & 0.48 & 0.20 & 0.36 & 0.20 & 0.44 \\
\hline$k_{7}$ & 0.60 & 0.20 & 0.16 & 0.64 & 0.36 & 0.40 & 0.00 & 0.56 & 0.36 & 0.48 & 0.60 & 0.16 & 0.20 & 0.12 & 0.68 \\
\hline$k_{8}$ & 0.20 & 0.56 & 0.56 & 0.20 & 0.35 & 0.28 & 0.56 & 0.00 & 0.35 & 0.48 & 0.20 & 0.52 & 0.24 & 0.56 & 0.15 \\
\hline$k_{9}$ & 0.44 & 0.28 & 0.12 & 0.56 & 0.28 & 0.36 & 0.24 & 0.52 & 0.00 & 0.44 & 0.44 & 0.16 & 0.44 & 0.56 & 0.40 \\
\hline$k_{10}$ & 0.20 & 0.40 & 0.20 & 0.52 & 0.44 & 0.24 & 0.32 & 0.20 & 0.44 & 0.00 & 0.20 & 0.52 & 0.16 & 0.24 & 0.12 \\
\hline$k_{11}$ & 0.24 & 0.20 & 0.20 & 0.12 & 0.16 & 0.52 & 0.52 & 0.60 & 0.16 & 0.44 & 0.00 & 0.10 & 0.16 & 0.56 & 0.32 \\
\hline$k_{12}$ & 0.44 & 0.44 & 0.40 & 0.44 & 0.64 & 0.36 & 0.24 & 0.20 & 0.64 & 0.20 & 0.44 & 0.00 & 0.30 & 0.52 & 0.24 \\
\hline$k_{13}$ & 0.44 & 0.08 & 0.24 & 0.36 & 0.20 & 0.16 & 0.20 & 0.36 & 0.20 & 0.24 & 0.44 & 0.08 & 0.00 & 0.08 & 0.20 \\
\hline$k_{14}$ & 0.24 & 0.44 & 0.40 & 0.24 & 0.32 & 0.56 & 0.40 & 0.20 & 0.32 & 0.16 & 0.24 & 0.24 & 0.32 & 0.00 & 0.40 \\
\hline$k_{15}$ & 0.24 & 0.16 & 0.24 & 0.48 & 0.28 & 0.36 & 0.16 & 0.20 & 0.28 & 0.12 & 0.24 & 0.20 & 0.20 & 0.32 & 0.00 \\
\hline
\end{tabular}

Step 3. Calculate the standard relative importance matrix. To more accurately calculate the importance degree between factors, we adopt Eq. (5) to compute the standard relative importance matrix (Table 8).

Step 4. Compute the initial direct relationship matrix. The initial direct relationship between factors depicts their degree of interaction with each other. Table 9 provides the initial direct relationship matrix, generated using Eq. (6) and Eq. (7).

Step 5. Normalize the initial direct relationship matrix based on Eq. (8).

Step 6. Construct total relationship matrix. Generate total relationship matrix (Table 10) using Eq. (9).

Table 8. Matrix of the standard relative importance considering the factors

\begin{tabular}{|c|c|c|c|c|c|c|c|c|}
\hline No. & $k_{1}$ & $k_{2}$ & $k_{3}$ & $k_{4}$ & $k_{5}$ & $k_{6}$ & $k_{7}$ & $k_{8}$ \\
\hline$k_{1}$ & 0.000 & 0.139 & 0.118 & 0.160 & 0.113 & 0.150 & 0.133 & 0.155 \\
\hline$k_{2}$ & 0.098 & 0.000 & 0.120 & 0.100 & 0.113 & 0.089 & 0.133 & 0.089 \\
\hline$k_{3}$ & 0.080 & 0.126 & 0.000 & 0.120 & 0.144 & 0.120 & 0.100 & 0.080 \\
\hline$k_{4}$ & 0.155 & 0.150 & 0.113 & 0.000 & 0.139 & 0.160 & 0.126 & 0.133 \\
\hline$k_{5}$ & 0.098 & 0.141 & 0.144 & 0.144 & 0.000 & 0.120 & 0.120 & 0.098 \\
\hline$k_{6}$ & 0.139 & 0.069 & 0.098 & 0.098 & 0.080 & 0.000 & 0.133 & 0.160 \\
\hline$k_{7}$ & 0.155 & 0.089 & 0.080 & 0.160 & 0.120 & 0.126 & 0.000 & 0.150 \\
\hline
\end{tabular}


End of Table 8

\begin{tabular}{|c|c|c|c|c|c|c|c|c|}
\hline No. & $k_{1}$ & $k_{2}$ & $k_{3}$ & $k_{4}$ & $k_{5}$ & $k_{6}$ & $k_{7}$ & $k_{8}$ \\
\hline$k_{8}$ & 0.089 & 0.150 & 0.150 & 0.089 & 0.118 & 0.106 & 0.150 & 0.000 \\
\hline$k_{9}$ & 0.133 & 0.106 & 0.069 & 0.150 & 0.106 & 0.120 & 0.098 & 0.144 \\
\hline$k_{10}$ & 0.089 & 0.126 & 0.089 & 0.144 & 0.133 & 0.098 & 0.113 & 0.089 \\
\hline$k_{11}$ & 0.098 & 0.089 & 0.089 & 0.069 & 0.080 & 0.144 & 0.144 & 0.155 \\
\hline$k_{12}$ & 0.133 & 0.133 & 0.126 & 0.133 & 0.160 & 0.120 & 0.098 & 0.089 \\
\hline$k_{13}$ & 0.133 & 0.057 & 0.098 & 0.120 & 0.089 & 0.080 & 0.089 & 0.120 \\
\hline$k_{14}$ & 0.098 & 0.133 & 0.126 & 0.098 & 0.113 & 0.150 & 0.126 & 0.089 \\
\hline$k_{15}$ & 0.098 & 0.080 & 0.098 & 0.139 & \begin{tabular}{|l|l|} 
& 0.106 \\
\end{tabular} & 0.120 & 0.080 & 0.089 \\
\hline No. & $k_{9}$ & $k_{10}$ & \multicolumn{2}{|c|}{$k_{11}$} & \begin{tabular}{l|l} 
\\
$k_{12}$
\end{tabular} & $k_{13}$ & $k_{14}$ & $k_{15}$ \\
\hline$k_{1}$ & 0.113 & 0.069 & \multicolumn{2}{|c|}{0.144} & 0.126 & 0.098 & 0.069 & 0.126 \\
\hline$k_{2}$ & 0.113 & 0.113 & \multicolumn{2}{|c|}{0.098} & 0.089 & 0.126 & 0.098 & 0.150 \\
\hline$k_{3}$ & 0.144 & 0.098 & \multicolumn{2}{|c|}{0.080} & 0.098 & 0.098 & 0.069 & 0.113 \\
\hline$k_{4}$ & 0.139 & 0.160 & & & 0.120 & 0.106 & 0.113 & 0.160 \\
\hline$k_{5}$ & 0.080 & 0.098 & & & 0.098 & 0.089 & 0.080 & 0.080 \\
\hline$k_{6}$ & 0.080 & 0.155 & & & 0.089 & 0.120 & 0.089 & 0.133 \\
\hline$k_{7}$ & 0.120 & 0.139 & & & 0.080 & 0.089 & 0.069 & 0.165 \\
\hline$k_{8}$ & 0.118 & 0.139 & & & 0.144 & 0.098 & 0.150 & 0.077 \\
\hline$k_{9}$ & 0.000 & 0.133 & & & 0.080 & 0.133 & 0.150 & 0.126 \\
\hline$k_{10}$ & 0.133 & 0.000 & & & 0.144 & 0.080 & 0.098 & 0.069 \\
\hline$k_{11}$ & 0.080 & 0.133 & & & 0.063 & 0.080 & 0.150 & 0.113 \\
\hline$k_{12}$ & 0.160 & 0.089 & & & 0.000 & 0.110 & 0.144 & 0.098 \\
\hline$k_{13}$ & 0.089 & 0.098 & & & 0.057 & 0.000 & 0.057 & 0.089 \\
\hline$k_{14}$ & 0.113 & 0.080 & & & 0.098 & 0.113 & 0.000 & 0.126 \\
\hline$k_{15}$ & 0.106 & 0.069 & & & 0.089 & 0.089 & 0.113 & 0.000 \\
\hline
\end{tabular}

Table 9. The initial direct relationship matrix

\begin{tabular}{|c|c|c|c|c|c|c|c|c|}
\hline No. & $k_{1}$ & $k_{2}$ & $k_{3}$ & $k_{4}$ & $k_{5}$ & $k_{6}$ & $k_{7}$ & $k_{8}$ \\
\hline$k_{1}$ & 0.0330 & 0.4470 & 0.3170 & 0.6070 & 0.2870 & 0.5270 & 0.4070 & 0.5670 \\
\hline$k_{2}$ & 0.2070 & 0.0330 & 0.3270 & 0.2170 & 0.2870 & 0.1670 & 0.4070 & 0.1670 \\
\hline$k_{3}$ & 0.1270 & 0.3670 & 0.0330 & 0.3270 & 0.4870 & 0.3270 & 0.2170 & 0.1270 \\
\hline$k_{4}$ & 0.5670 & 0.5270 & 0.2870 & 0.0330 & 0.4470 & 0.6070 & 0.3670 & 0.4070 \\
\hline$k_{5}$ & 0.2070 & 0.4670 & 0.4870 & 0.4870 & 0.0330 & 0.3270 & 0.3270 & 0.2070 \\
\hline$k_{6}$ & 0.4470 & 0.0870 & 0.2070 & 0.2070 & 0.1270 & 0.0330 & 0.4070 & 0.6070 \\
\hline$k_{7}$ & 0.5670 & 0.1670 & 0.1270 & 0.6070 & 0.3270 & 0.3670 & 0.0330 & 0.5270 \\
\hline$k_{8}$ & 0.1670 & 0.5270 & 0.5270 & 0.1670 & 0.3170 & 0.2470 & 0.5270 & 0.0330 \\
\hline$k_{9}$ & 0.4070 & 0.2470 & 0.0870 & 0.5270 & 0.2470 & 0.3270 & 0.2070 & 0.4870 \\
\hline$k_{10}$ & 0.1670 & 0.3670 & 0.1670 & 0.4870 & 0.4070 & 0.2070 & 0.2870 & 0.1670 \\
\hline$k_{11}$ & 0.2070 & 0.1670 & 0.1670 & 0.0870 & 0.1270 & 0.4870 & 0.4870 & 0.5670 \\
\hline$k_{12}$ & 0.4070 & 0.4070 & 0.3670 & 0.4070 & 0.6070 & 0.3270 & 0.2070 & 0.1670 \\
\hline$k_{13}$ & 0.4070 & 0.0470 & 0.2070 & 0.3270 & 0.1670 & 0.1270 & 0.1670 & 0.3270 \\
\hline$k_{14}$ & 0.2070 & 0.4070 & 0.3670 & 0.2070 & 0.2870 & 0.5270 & 0.3670 & 0.1670 \\
\hline$k_{15}$ & 0.2070 & 0.1270 & 0.2070 & 0.4470 & 0.2470 & 0.3270 & 0.1270 & 0.1670 \\
\hline
\end{tabular}


End of Table 9

\begin{tabular}{|c|c|c|c|c|c|c|c|}
\hline No. & $k_{9}$ & $k_{10}$ & $k_{11}$ & $k_{12}$ & $k_{13}$ & $k_{14}$ & $k_{15}$ \\
\hline$k_{1}$ & 0.2870 & 0.0870 & 0.4870 & 0.3670 & 0.2070 & 0.0870 & 0.3670 \\
\hline$k_{2}$ & 0.2870 & 0.2870 & 0.2070 & 0.1670 & 0.3670 & 0.2070 & 0.5270 \\
\hline$k_{3}$ & 0.4870 & 0.2070 & 0.1270 & 0.2070 & 0.2070 & 0.0870 & 0.2870 \\
\hline$k_{4}$ & 0.4470 & 0.6070 & 0.5670 & 0.3270 & 0.2470 & 0.2870 & 0.6070 \\
\hline$k_{5}$ & 0.1270 & 0.2070 & 0.2070 & 0.2070 & 0.1670 & 0.1270 & 0.1270 \\
\hline$k_{6}$ & 0.1270 & 0.5670 & 0.4470 & 0.1670 & 0.3270 & 0.1670 & 0.4070 \\
\hline$k_{7}$ & 0.3270 & 0.4470 & 0.5670 & 0.1270 & 0.1670 & 0.0870 & 0.6470 \\
\hline$k_{8}$ & 0.3170 & 0.4470 & 0.1670 & 0.4870 & 0.2070 & 0.5270 & 0.1170 \\
\hline$k_{9}$ & 0.0330 & 0.4070 & 0.4070 & 0.1270 & 0.4070 & 0.5270 & 0.3670 \\
\hline$k_{10}$ & 0.4070 & 0.0330 & 0.1670 & 0.4870 & 0.1270 & 0.2070 & 0.0870 \\
\hline$k_{11}$ & 0.1270 & 0.4070 & 0.0330 & 0.0670 & 0.1270 & 0.5270 & 0.2870 \\
\hline$k_{12}$ & 0.6070 & 0.1670 & 0.4070 & 0.0330 & 0.2670 & 0.4870 & 0.2070 \\
\hline$k_{13}$ & 0.1670 & 0.2070 & 0.4070 & 0.0470 & 0.0330 & 0.0470 & 0.1670 \\
\hline$k_{14}$ & 0.2870 & 0.1270 & 0.2070 & 0.2070 & 0.2870 & 0.0330 & 0.3670 \\
\hline$k_{15}$ & 0.2470 & 0.0870 & 0.2070 & 0.1670 & 0.1670 & 0.2870 & 0.0330 \\
\hline
\end{tabular}

Table 10. Total relationship matrix

\begin{tabular}{|c|c|c|c|c|c|c|c|c|}
\hline No. & $k_{1}$ & $k_{2}$ & $k_{3}$ & $k_{4}$ & $k_{5}$ & $k_{6}$ & $k_{7}$ & $k_{8}$ \\
\hline$k_{1}$ & 0.1268 & 0.1882 & 0.1557 & 0.2272 & 0.1629 & 0.2158 & 0.1905 & 0.2191 \\
\hline$k_{2}$ & 0.1194 & 0.0911 & 0.1259 & 0.1380 & 0.1306 & 0.1246 & 0.1511 & 0.1208 \\
\hline$k_{3}$ & 0.1054 & 0.1401 & 0.0796 & 0.1497 & 0.1569 & 0.1440 & 0.1210 & 0.1122 \\
\hline$k_{4}$ & 0.2262 & 0.2221 & 0.1706 & 0.1731 & 0.2083 & 0.2528 & 0.2083 & 0.2202 \\
\hline$k_{5}$ & 0.1205 & 0.1598 & 0.1516 & 0.1745 & 0.0945 & 0.1493 & 0.1430 & 0.1276 \\
\hline$k_{6}$ & 0.1655 & 0.1153 & 0.1207 & 0.1490 & 0.1193 & 0.1182 & 0.1687 & 0.2019 \\
\hline$k_{7}$ & 0.2037 & 0.1476 & 0.1260 & 0.2299 & 0.1668 & 0.1938 & 0.1335 & 0.2136 \\
\hline$k_{8}$ & 0.1351 & 0.1911 & 0.1774 & 0.1554 & 0.1612 & 0.1611 & 0.1940 & 0.1212 \\
\hline$k_{9}$ & 0.1725 & 0.1514 & 0.1144 & 0.2066 & 0.1471 & 0.1781 & 0.1521 & 0.1964 \\
\hline$k_{10}$ & 0.1195 & 0.1501 & 0.1078 & 0.1806 & 0.1549 & 0.1362 & 0.1396 & 0.1251 \\
\hline$k_{11}$ & 0.1203 & 0.1159 & 0.1063 & 0.1172 & 0.1079 & 0.1745 & 0.1704 & 0.1840 \\
\hline$k_{12}$ & 0.1780 & 0.1807 & 0.1603 & 0.1979 & 0.2062 & 0.1847 & 0.1561 & 0.1553 \\
\hline$k_{13}$ & 0.1292 & 0.0783 & 0.0926 & 0.1289 & 0.0931 & 0.0995 & 0.1001 & 0.1277 \\
\hline$k_{14}$ & 0.1253 & 0.1515 & 0.1369 & 0.1397 & 0.1345 & 0.1828 & 0.1525 & 0.1284 \\
\hline$k_{15}$ & 0.1062 & 0.0945 & 0.0971 & 0.1513 & 0.1102 & 0.1348 & 0.0977 & 0.1073 \\
\hline
\end{tabular}


End of Table 10

\begin{tabular}{|c|c|c|c|c|c|c|c|}
\hline No. & $k_{9}$ & $k_{10}$ & $k_{11}$ & $k_{12}$ & $k_{13}$ & $k_{14}$ & $k_{15}$ \\
\hline$k_{1}$ & 0.1599 & 0.1413 & 0.2021 & 0.1455 & 0.1237 & 0.1199 & 0.1868 \\
\hline$k_{2}$ & 0.1282 & 0.1309 & 0.1246 & 0.0902 & 0.1216 & 0.1049 & 0.1730 \\
\hline$k_{3}$ & 0.1540 & 0.1188 & 0.1100 & 0.0938 & 0.0976 & 0.0860 & 0.1348 \\
\hline$k_{4}$ & 0.2044 & 0.2362 & 0.2359 & 0.1583 & 0.1469 & 0.1675 & 0.2434 \\
\hline$k_{5}$ & 0.1071 & 0.1236 & 0.1256 & 0.0979 & 0.0933 & 0.0928 & 0.1177 \\
\hline$k_{6}$ & 0.1171 & 0.1869 & 0.1727 & 0.1047 & 0.1231 & 0.1128 & 0.1655 \\
\hline$k_{7}$ & 0.1637 & 0.1910 & 0.2124 & 0.1129 & 0.1149 & 0.1195 & 0.2240 \\
\hline$k_{8}$ & 0.1582 & 0.1772 & 0.1409 & 0.1556 & 0.1169 & 0.1717 & 0.1377 \\
\hline$k_{9}$ & 0.1117 & 0.1756 & 0.1799 & 0.1058 & 0.1461 & 0.1757 & 0.1746 \\
\hline$k_{10}$ & 0.1520 & 0.0992 & 0.1247 & 0.1418 & 0.0909 & 0.1115 & 0.1137 \\
\hline$k_{11}$ & 0.1059 & 0.1541 & 0.0987 & 0.0807 & 0.0876 & 0.1560 & 0.1397 \\
\hline$k_{12}$ & 0.2024 & 0.1446 & 0.1857 & 0.0909 & 0.1318 & 0.1736 & 0.1586 \\
\hline$k_{13}$ & 0.0914 & 0.1027 & 0.1348 & 0.0609 & 0.0556 & 0.0675 & 0.0985 \\
\hline$k_{14}$ & 0.1320 & 0.1148 & 0.1307 & 0.0989 & 0.1154 & 0.0820 & 0.1568 \\
\hline$k_{15}$ & 0.1082 & 0.0900 & 0.1108 & 0.0804 & 0.0822 & 0.1065 & 0.0849 \\
\hline
\end{tabular}

Step 7. Identify CSFs. Using Eq. (10) and Eq. (11), we calculate $R_{i}$ and $C_{j}$, leading to the overall dominance $P_{i}$ and the causal degree $E_{i}$ (Table 11).

Table 11. Effect and cause relationships between factors

\begin{tabular}{|c|c|c|c|c|}
\hline No. & $R_{i}$ & $C_{j}$ & $P_{i}$ & $E_{i}$ \\
\hline$k_{1}$ & 2.57 & 2.15 & 4.72 & 0.41 \\
\hline$k_{2}$ & 1.87 & 2.18 & 4.05 & -0.30 \\
\hline$k_{3}$ & 1.80 & 1.92 & 3.73 & -0.12 \\
\hline$k_{4}$ & 3.07 & 2.52 & 5.59 & 0.56 \\
\hline$k_{5}$ & 1.88 & 2.15 & 4.03 & -0.28 \\
\hline$k_{6}$ & 2.14 & 2.45 & 4.59 & -0.31 \\
\hline$k_{7}$ & 2.55 & 2.28 & 4.83 & 0.27 \\
\hline$k_{8}$ & 2.35 & 2.36 & 4.72 & -0.01 \\
\hline$k_{9}$ & 2.39 & 2.10 & 4.48 & 0.29 \\
\hline$k_{10}$ & 1.95 & 2.19 & 4.13 & -0.24 \\
\hline$k_{11}$ & 1.92 & 2.29 & 4.21 & -0.37 \\
\hline$k_{12}$ & 2.51 & 1.62 & 4.13 & 0.89 \\
\hline$k_{13}$ & 1.46 & 1.65 & 3.11 & -0.19 \\
\hline$k_{14}$ & 1.98 & 1.85 & 3.83 & 0.13 \\
\hline$k_{15}$ & 1.56 & 2.31 & 3.87 & -0.75 \\
\hline
\end{tabular}




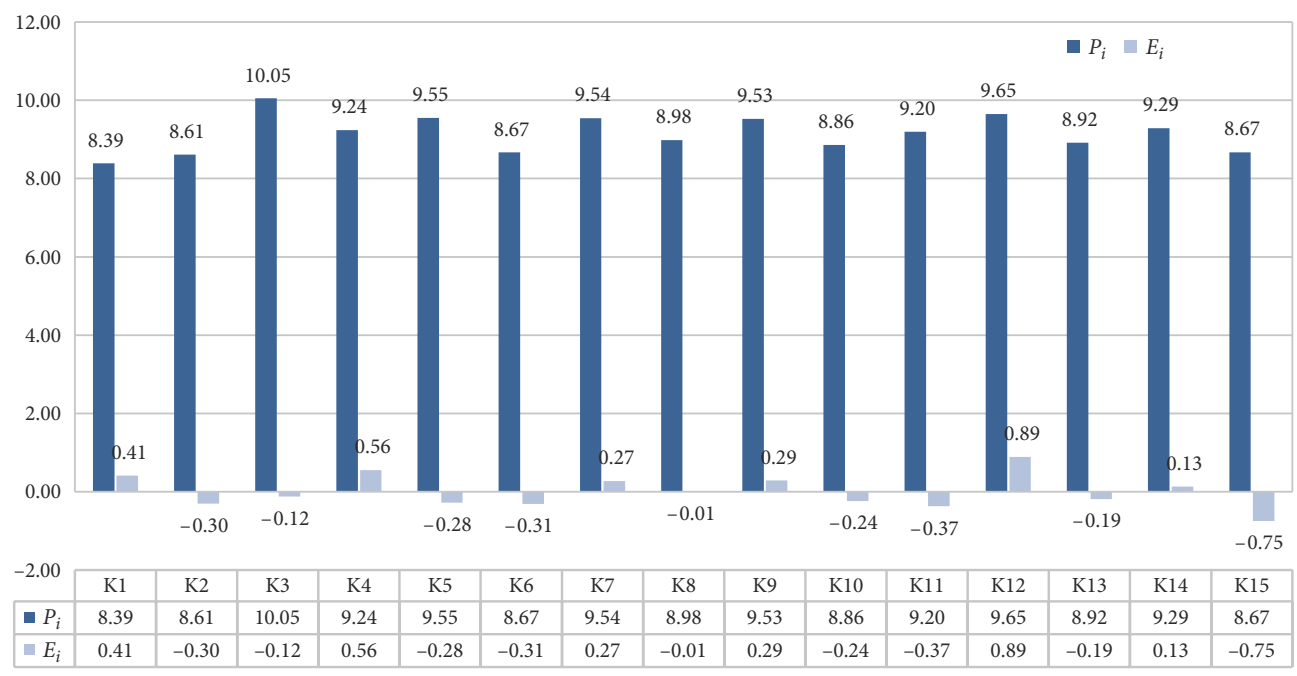

Figure 2. The cause-effect graph of supplier selection factors

Figure 2 provides the resulting cause-effect diagram, according to the values of $P_{i}$ and $E_{i}$ calculated by using Eq. (12) and (13) in Table 11. Figure 2 shows that factors are segmented into two different groups based on the values of causal degree $E_{i}$. For $E_{i}<0(i=2,3,5,6,8,10,11,13,15), \kappa_{2}, \kappa_{3}, \kappa_{6}, \kappa_{8}, \kappa_{10}, \kappa_{11}, \kappa_{13}$ and $\kappa_{15}$ form the net effect group. For $E_{i}>0(i=1,4,7,9,12,14), \kappa_{1}, \kappa_{4}, \kappa_{7}, \kappa_{9}, \kappa_{12}$ and $\kappa_{14}$ form the net cause group. This indicates they have overall effects on the entire factor system. Therefore, we identify the factors $\kappa_{1}^{\prime}, \kappa_{4}^{\prime}$, $\kappa_{7}^{\prime}, \kappa_{9}^{\prime}, \kappa_{12}^{\prime}, \kappa_{14}^{\prime}$ as CSFs.

\subsection{The decision-making process using the TODIM method under PLTSs}

After completing calculations using the PLTSs and DEMATEL method, the CSFs $\kappa_{1}^{\prime}, \kappa_{4}^{\prime}, \kappa_{7}^{\prime}$, $\kappa_{9}^{\prime}, \kappa_{12}^{\prime}$ and $\kappa_{14}^{\prime}$ are identified as the CSFs for selecting the most suitable sustainable NEV suppliers. Five alternatives are identified to serve as sustainable NEV suppliers: $\pi_{1}, \pi_{2}, \pi_{3}$, $\pi_{4}$ and $\pi_{5}$.

Step 1. We use questionnaires (in Supplementary information) to collect 5 experts' evaluation on potential suppliers' performance. Using the established linguistic term scale for sustainable supplier selection (Table 5), we generate the initial probabilistic linguistic evaluation matrix (Table 12).

Step 2. Calculate NPLTSs and transform cost attributes into benefit attributes. By transforming the initial probabilistic linguistic evaluation matrix into NPLTSs, $\kappa_{7}^{\prime}$ and $\kappa_{9}^{\prime}$ are identified as cost attributes. According to negation operation $(\mathrm{Xu}, 2012)$, we transform them into benefit attributes. Table 13 displays the results.

Step 3. Compute relative weights of CSFs. On the basis of entropy weighting approach with DEMATEL method, the weight vector of CSFs in this paper is $w_{\lambda}=(0.164,0.160,0.170$, $0.169,0.156,0.180)^{\mathrm{T}}$. We select the largest weight as the referential weight $\max w_{\lambda}=w_{6}$. 
The relative weight $w_{\lambda / \lambda^{*}}$ is further calculated as $w_{\lambda / \lambda^{*}}=\frac{w_{\lambda}}{\max w_{\lambda}}(\lambda=1,2, \ldots, s ; 1 \leq s \leq n)$. This leads to: $w_{1 / \lambda^{*}}=0.915, w_{2 / \lambda^{*}}=0.892, w_{3 / \lambda^{*}}=0.948, w_{4 / \lambda^{*}}=0.943, w_{5 / \lambda^{*}}=0.870$, and $=1.000$.

Table 12. Initial probabilistic linguistic evaluation matrix

\begin{tabular}{|c|c|c|c|}
\hline & $\kappa_{1}^{\prime}{ }_{1}$ & $\kappa_{4}^{\prime}$ & $\kappa^{\prime}{ }_{7}$ \\
\hline$\pi_{1}$ & $\left\{S_{1}(0.2), S_{2}(0.6), S_{3}(0.2)\right\}$ & $\left\{S_{-1}(0.2), S_{1}(0.2), S_{2}(0.6)\right\}$ & $\left\{S_{-3}(0.4), S_{-1}(0.2), S_{2}(0.4)\right\}$ \\
\hline$\pi_{2}$ & $\left\{S_{-3}(1)\right\}$ & $\left\{S_{-2}(0.4), S_{0}(0.4)\right\}$ & $\left\{S_{-2}(0.5), S_{-1}(0.5)\right\}$ \\
\hline$\pi_{3}$ & $\left\{S_{2}(0.2), S_{3}(0.8)\right\}$ & $\left\{S_{0}(0.6), S_{2}(0.4)\right\}$ & $\left\{S_{-2}(0.2), S_{0}(0.6)\right\}$ \\
\hline$\pi_{4}$ & $\left\{S_{1}(0.4), S_{3}(0.6)\right\}$ & $\left\{S_{0}(0.4), S_{2}(0.4), S_{3}(0.2)\right\}$ & $\left\{S_{-1}(0.8), S_{0}(0.2)\right\}$ \\
\hline$\pi_{5}$ & $\left\{S_{1}(0.4), S_{2}(0.6)\right\}$ & $\left\{S_{-1}(0.4), S_{2}(0.4), S_{3}(0.2)\right\}$ & $\left\{S_{-2}(0.6), S_{-1}(0.2), S_{3}(0.2)\right\}$ \\
\hline & $\kappa^{\prime}{ }_{9}$ & $\kappa_{12}^{\prime}$ & $\kappa_{14}^{\prime}$ \\
\hline$\pi_{1}$ & $\left\{S_{-3}(0.4), S_{-2}(0.4)\right\}$ & $\left\{S_{-2}(0.5), S_{0}(0.5)\right\}$ & $\left\{S_{1}(0.2), S_{2}(0.6)\right\}$ \\
\hline$\pi_{2}$ & $\left\{S_{0}(0.4), S_{2}(0.2), S_{3}(0.4)\right\}$ & $\left\{S_{-2}(0.2), S_{-1}(0.6), S_{0}(0.2)\right\}$ & $\left\{S_{-2}(0.8), S_{0}(0.2)\right\}$ \\
\hline$\pi_{3}$ & $\left\{S_{-3}(0.2), S_{-2}(0.4), S_{1}(0.2)\right\}$ & $\left\{S_{0}(0.6), S_{2}(0.2)\right\}$ & $\left\{S_{-3}(0.2), S_{-2}(0.6), S_{0}(0.2)\right\}$ \\
\hline$\pi_{4}$ & $\left\{S_{-2}(0.4), S_{-1}(0.6)\right\}$ & $\left\{S_{1}(0.8), S_{2}(0.2)\right\}$ & $\left\{S_{0}(0.2), S_{2}(0.6), S_{3}(0.2)\right\}$ \\
\hline$\pi_{5}$ & $\left\{S_{-2}(0.2), S_{0}(0.2), S_{3}(0.6)\right\}$ & $\left\{S_{1}(0.6), S_{2}(0.2), S_{3}(0.2)\right\}$ & $\left\{S_{-1}(0.6), S_{0}(0.2), S_{2}(0.2)\right\}$ \\
\hline
\end{tabular}

Table 13. Evaluation matrix of NPLTSs

\begin{tabular}{|c|c|c|c|}
\hline & $\kappa_{1}^{\prime}$ & $\kappa^{\prime}{ }_{4}$ & $\kappa^{\prime}$ \\
\hline$\pi_{1}$ & $\left\{S_{1}(0.2), S_{2}(0.6), S_{3}(0.2)\right\}$ & $\left\{S_{-1}(0.2), S_{1}(0.2), S_{2}(0.6)\right\}$ & $\left\{S_{-2}(0.4), S_{1}(0.2), S_{3}(0.4)\right\}$ \\
\hline$\pi_{2}$ & $\left\{S_{-3}(0), S_{-3}(0), S_{-3}(1)\right\}$ & $\left\{S_{-2}(0), S_{-2}(0.4), S_{0}(0.4)\right\}$ & $\left\{S_{1}(0.5), S_{2}(0), S_{2}(0.5)\right\}$ \\
\hline$\pi_{3}$ & $\left\{S_{2}(0), S_{2}(0.2), S_{3}(0.8)\right\}$ & $\left\{S_{0}(0), S_{0}(0.2), S_{2}(0.8)\right\}$ & $\left\{S_{0}(0.6), S_{2}(0), S_{2}(0.2)\right\}$ \\
\hline$\pi_{4}$ & $\left\{S_{1}(0), S_{1}(0.4), S_{3}(0.6)\right\}$ & $\left\{S_{0}(0.4), S_{2}(0.4), S_{3}(0.2)\right\}$ & $\left\{S_{0}(0.2), S_{1}(0), S_{1}(0.8)\right\}$ \\
\hline$\pi_{5}$ & $\left\{S_{1}(0), S_{1}(0.4), S_{2}(0.6)\right\}$ & $\left\{S_{-1}(0.4), S_{2}(0.4), S_{3}(0.2)\right\}$ & $\left\{S_{-3}(0.2), S_{1}(0.2), S_{2}(0.6)\right\}$ \\
\hline & $\kappa^{\prime}{ }_{9}^{\prime}$ & $\kappa_{12}^{\prime}$ & $\kappa_{14}^{\prime}$ \\
\hline$\pi_{1}$ & $\left\{S_{2}(0.4), S_{3}(0), S_{3}(0.4)\right\}$ & $\left\{S_{-2}(0), S_{-2}(0.5), S_{1}(0.5)\right\}$ & $\left\{S_{1}(0), S_{1}(0.2), S_{2}(0.6)\right\}$ \\
\hline$\pi_{2}$ & $\left\{S_{0}(0.4), S_{2}(0.2), S_{3}(0.4)\right\}$ & $\left\{S_{-2}(0.2), S_{-1}(0.6), S_{2}(0.2)\right\}$ & $\left\{S_{-2}(0), S_{-2}(0.8), S_{1}(0.2)\right\}$ \\
\hline$\pi_{3}$ & $\left\{S_{-1}(0.2), S_{2}(0.4), S_{3}(0.2)\right\}$ & $\left\{S_{0}(0.2), S_{1}(0.6), S_{2}(0.2)\right\}$ & $\left\{S_{-3}(0.2), S_{-2}(0.6), S_{0}(0.2)\right\}$ \\
\hline$\pi_{4}$ & $\left\{S_{1}(0.6), S_{2}(0), S_{2}(0.4)\right\}$ & $\left\{S_{1}(0), S_{1}(0.8), S_{2}(0.2)\right\}$ & $\left\{S_{1}(0.2), S_{2}(0.6), S_{3}(0.2)\right\}$ \\
\hline$\pi_{5}$ & $\left\{S_{-2}(0.2), S_{0}(0.2), S_{3}(0.6)\right\}$ & $\left\{S_{1}(0.6), S_{2}(0.2), S_{3}(0.2)\right\}$ & $\left\{S_{-1}(0.6), S_{0}(0.2), S_{2}(0.2)\right\}$ \\
\hline
\end{tabular}

Step 4. Calculate the dominance matrix $\varphi_{\lambda}^{\prime}\left(\pi_{x}, \pi_{y}\right)$. Using Definitions 2 and 3 , we assign $\zeta=0.1$ to obtain the comparative results of any two sustainable suppliers, in the case of a loss in generality.

For example, when considering $\kappa_{1}^{\prime}$ (Technology capability), the evaluation value of $\pi_{1}$ is $\left\{S_{1}(0.2), S_{2}(0.6), S_{3}(0.2)\right\}$, while the value of $\pi_{2}$ is $\left\{S_{-3}(0), S_{-3}(0), S_{-3}(1)\right\}$. Calculating $S^{\zeta}(L(p))$ (Eq. (5)) resulted in $S^{0.1}\left(L(p)_{11}\right)=31797.8629>S^{0.1}\left(L(p)_{21}\right)=3.0000$. This means that supplier $\pi_{1}$ is rated as better than supplier $\pi_{2}$ when take the consideration of financial capacity, denoted as $\left(\pi_{1}>\pi_{2}\right)^{\kappa_{12}^{\prime}}$. Similarly, Table 14 shows the pairwise comparison of suppliers considering different CSFs. 
For the sake of generality, let $\mu=1$. We adopt Eq. (17) to determine the dominance degree of the sustainable supplier $\pi_{x}$ over the other supplier $\pi_{y}$ considering each CSF. And the results are shown in Tables 15-20.

Table 14. Pairwise comparison of sustainable suppliers' benefit and loss

\begin{tabular}{|c|c|c|c|c|c|}
\hline & $\pi_{1} / \pi_{2}$ & $\pi_{1} / \pi_{3}$ & $\pi_{1} / \pi_{4}$ & $\pi_{1} / \pi_{5}$ & $\pi_{2} / \pi_{3}$ \\
\hline$\kappa_{1}^{\prime}$ & $\left(\pi_{1}>\pi_{2}\right)^{k^{\prime} 1}$ & $\left(\pi_{1}>\pi_{3}\right)^{k^{\prime} 1}$ & $\left(\pi_{1}>\pi_{4}\right)^{k^{\prime} 1}$ & $\left(\pi_{1}>\pi_{5}\right)^{k^{\prime} 1}$ & $\left(\pi_{2}<\pi_{3}\right)^{k^{\prime} 1}$ \\
\hline$\kappa_{4}^{\prime}$ & $\left(\pi_{1}>\pi_{2}\right)^{k^{\prime} 4}$ & $\left(\pi_{1}>\pi_{3}\right)^{k^{\prime} 4}$ & $\left(\pi_{1}>\pi_{4}\right)^{k^{\prime} 4}$ & $\left(\pi_{1}<\pi_{5}\right)^{k^{\prime} 4}$ & $\left(\pi_{2}<\pi_{3}\right)^{k^{\prime} 4}$ \\
\hline$\kappa_{7}^{\prime}$ & $\left(\pi_{1}>\pi_{2}\right)^{k^{\prime} 7}$ & $\left(\pi_{1}>\pi_{3}\right)^{k^{\prime} 7}$ & $\left(\pi_{1}>\pi_{4}\right)^{k^{\prime} 7}$ & $\left(\pi_{1}>\pi_{5}\right)^{k^{\prime} 7}$ & $\left(\pi_{2}>\pi_{3}\right)^{k^{\prime} 7}$ \\
\hline$\kappa_{9}^{\prime}$ & $\left(\pi_{1}>\pi_{2}\right)^{k^{\prime} 9}$ & $\left(\pi_{1}<\pi_{3}\right)^{k^{\prime} 9}$ & $\left(\pi_{1}>\pi_{4}\right)^{k^{\prime} 9}$ & $\left(\pi_{1}>\pi_{5}\right)^{k^{\prime} 9}$ & $\left(\pi_{2}<\pi_{3}\right)^{k^{\prime} 9}$ \\
\hline$\kappa_{12}^{\prime}$ & $\left(\pi_{1}<\pi_{2}\right)^{\mathrm{k}^{\prime} 12}$ & $\left(\pi_{1}<\pi_{3}\right)^{\mathrm{k}^{\prime} 12}$ & $\left(\pi_{1}<\pi_{4}\right)^{\mathrm{k}^{\prime} 12}$ & $\left(\pi_{1}>\pi_{5}\right)^{\mathrm{k}^{\prime} 12}$ & $\left(\pi_{2}<\pi_{3}\right)^{k^{\prime} 12}$ \\
\hline$\kappa_{14}^{\prime}$ & $\left(\pi_{1}<\pi_{2}\right)^{\mathrm{k}^{\prime} 14}$ & $\left(\pi_{1}>\pi_{3}\right)^{\mathrm{k}^{\prime} 14}$ & $\left(\pi_{1}>\pi_{4}\right)^{k^{\prime} 14}$ & $\left(\pi_{1}<\pi_{5}\right)^{k^{\prime} 14}$ & $\left(\pi_{2}>\pi_{3}\right)^{k^{\prime} 14}$ \\
\hline & $\pi_{2} / \pi_{4}$ & $\pi_{2} / \pi_{5}$ & $\pi_{3} / \pi_{4}$ & $\pi_{3} / \pi_{5}$ & $\pi_{4} / \pi_{5}$ \\
\hline$\kappa_{1}^{\prime}$ & $\left(\pi_{2}<\pi_{4}\right)^{\mathrm{k}^{\prime} 1}$ & $\left(\pi_{2}<\pi_{5}\right)^{\mathrm{k}^{\prime} 1}$ & $\left(\pi_{3}>\pi_{4}\right)^{\mathrm{k}^{\prime} 1}$ & $\left(\pi_{3}>\pi_{5}\right)^{\mathrm{k}^{\prime} 1}$ & $\left(\pi_{4}>\pi_{5}\right)^{\mathrm{k}^{\prime} 1}$ \\
\hline$\kappa_{4}^{\prime}$ & $\left(\pi_{2}<\pi_{4}\right)^{k^{\prime} 4}$ & $\left(\pi_{2}<\pi_{5}\right)^{k^{\prime} 4}$ & $\left(\pi_{3}<\pi_{4}\right)^{k^{\prime} 4}$ & $\left(\pi_{3}<\pi_{5}\right)^{k^{\prime} 4}$ & $\left(\pi_{4}<\pi_{5}\right)^{k^{\prime} 4}$ \\
\hline$\kappa_{7}^{\prime}$ & $\left(\pi_{2}>\pi_{4}\right)^{k^{\prime} 7}$ & $\left(\pi_{2}<\pi_{5}\right)^{k^{\prime} 7}$ & $\left(\pi_{3}<\pi_{4}\right)^{k^{\prime} 7}$ & $\left(\pi_{3}<\pi_{5}\right)^{k^{\prime} 7}$ & $\left(\pi_{4}<\pi_{5}\right)^{k^{\prime} 7}$ \\
\hline$\kappa_{9}^{\prime}$ & $\left(\pi_{2}>\pi_{4}\right)^{\mathrm{k}^{\prime} 9}$ & $\left(\pi_{2}<\pi_{5}\right)^{\mathrm{k}^{\prime} 9}$ & $\left(\pi_{3}>\pi_{4}\right)^{\mathrm{k}^{\prime} 9}$ & $\left(\pi_{3}>\pi_{5}\right)^{\mathrm{k}^{\prime} 9}$ & $\left(\pi_{4}<\pi_{5}\right)^{\mathrm{k}^{\prime} 9}$ \\
\hline$\kappa_{12}^{\prime}$ & $\left(\pi_{2}<\pi_{4}\right)^{\mathrm{k}^{\prime} 12}$ & $\left(\pi_{2}>\pi_{5}\right)^{\mathrm{k}^{\prime} 12}$ & $\left(\pi_{3}<\pi_{4}\right)^{\mathrm{k}^{\prime} 12}$ & $\left(\pi_{3}>\pi_{5}\right)^{\mathrm{k}^{\prime} 12}$ & $\left(\pi_{4}>\pi_{5}\right)^{\mathrm{k}^{\prime} 12}$ \\
\hline$\kappa_{14}^{\prime}$ & $\left(\pi_{2}>\pi_{4}\right)^{\mathrm{k}^{\prime} 14}$ & $\left(\pi_{2}>\pi_{5}\right)^{\mathrm{k}^{\prime} 14}$ & $\left(\pi_{3}<\pi_{4}\right)^{\mathrm{k}^{\prime} 14}$ & $\left(\pi_{3}<\pi_{5}\right)^{k^{\prime} 14}$ & $\left(\pi_{4}<\pi_{5}\right)^{k^{\prime} 14}$ \\
\hline
\end{tabular}

Table 15. The dominance degree of supplier $\pi_{x}$ over supplier $\pi_{y}$ concerning the CSF $\kappa^{\prime}{ }_{1}$

\begin{tabular}{|c|c|c|c|c|c|}
\hline$\kappa_{1}^{\prime}$ & $\pi_{1}$ & $\pi_{2}$ & $\pi_{3}$ & $\pi_{4}$ & $\pi_{5}$ \\
\hline$\pi_{1}$ & 0.0000 & 0.1002 & 0.0905 & 0.0467 & 0.0687 \\
\hline$\pi_{2}$ & -0.6102 & 0.0000 & -0.2623 & -0.5398 & -0.7397 \\
\hline$\pi_{3}$ & -0.5509 & 0.0431 & 0.0000 & 0.0775 & 0.1136 \\
\hline$\pi_{4}$ & -0.2843 & 0.0887 & -0.4719 & 0.0000 & 0.0831 \\
\hline$\pi_{5}$ & -0.4182 & 0.1215 & -0.6916 & -0.5057 & 0.0000 \\
\hline
\end{tabular}

Table 16. The dominance degree of supplier $\pi_{x}$ over supplier $\pi_{y}$ concerning the CSF $\kappa^{\prime}{ }_{4}$

\begin{tabular}{|c|c|c|c|c|c|}
\hline$\kappa_{4}^{\prime}$ & $\pi_{1}$ & $\pi_{2}$ & $\pi_{3}$ & $\pi_{4}$ & $\pi_{5}$ \\
\hline$\pi_{1}$ & 0.0000 & 0.1301 & 0.0000 & 0.1975 & -0.3036 \\
\hline$\pi_{2}$ & -0.8124 & 0.0000 & -0.8124 & -0.7496 & -0.8673 \\
\hline$\pi_{3}$ & 0.0000 & 0.1301 & 0.0000 & -0.3133 & -0.3036 \\
\hline$\pi_{4}$ & -0.3133 & 0.1201 & 0.0502 & 0.0000 & -0.4363 \\
\hline$\pi_{5}$ & 0.0486 & 0.1389 & 0.0486 & 0.0699 & 0.0000 \\
\hline
\end{tabular}


Table 17. The dominance degree of supplier $\pi_{x}$ over supplier $\pi_{y}$ concerning the CSF $\kappa^{\prime}{ }_{7}$

\begin{tabular}{|c|c|c|c|c|c|}
\hline$\kappa^{\prime}{ }_{7}$ & $\pi_{1}$ & $\pi_{2}$ & $\pi_{3}$ & $\pi_{4}$ & $\pi_{5}$ \\
\hline$\pi_{1}$ & 0.0000 & 0.0920 & 0.1789 & 0.1389 & 0.0476 \\
\hline$\pi_{2}$ & -0.5405 & 0.0000 & 0.1535 & 0.1040 & -0.4628 \\
\hline$\pi_{3}$ & -1.0510 & -0.9014 & 0.0000 & -0.6626 & -1.0132 \\
\hline$\pi_{4}$ & -0.8158 & -0.6110 & 0.1128 & 0.0000 & -0.7665 \\
\hline$\pi_{5}$ & -0.2793 & 0.0788 & 0.1725 & 0.1305 & 0.0000 \\
\hline
\end{tabular}

Table 18. The dominance degree of supplier $\pi_{x}$ over supplier $\pi_{y}$ concerning the CSF $\kappa^{\prime}{ }_{9}$

\begin{tabular}{|c|c|c|c|c|c|}
\hline$\kappa^{\prime}{ }_{9}$ & $\pi_{1}$ & $\pi_{2}$ & $\pi_{3}$ & $\pi_{4}$ & $\pi_{5}$ \\
\hline$\pi_{1}$ & 0.0000 & 0.0660 & -0.3895 & 0.0411 & 0.1071 \\
\hline$\pi_{2}$ & -0.3895 & 0.0000 & 0.0000 & 0.0516 & -0.4980 \\
\hline$\pi_{3}$ & 0.0660 & 0.0000 & 0.0000 & 0.0516 & 0.0844 \\
\hline$\pi_{4}$ & -0.2427 & -0.3046 & -0.3046 & 0.0000 & -0.4980 \\
\hline$\pi_{5}$ & -0.6322 & 0.0844 & -0.4980 & 0.0989 & 0.0000 \\
\hline
\end{tabular}

Table 19. The dominance degree of supplier $\pi_{x}$ over supplier $\pi_{y}$ concerning the CSF $\kappa_{12}^{\prime}$

\begin{tabular}{|c|c|c|c|c|c|}
\hline$\kappa^{\prime}{ }_{12}$ & $\pi_{1}$ & $\pi_{2}$ & $\pi_{3}$ & $\pi_{4}$ & $\pi_{5}$ \\
\hline$\pi_{1}$ & 0.0000 & -0.2218 & 0.0838 & 0.0636 & -0.2181 \\
\hline$\pi_{2}$ & 0.0360 & 0.0000 & 0.0757 & 0.0524 & -0.3110 \\
\hline$\pi_{3}$ & -0.5159 & -0.4658 & 0.0000 & -0.3362 & -0.5601 \\
\hline$\pi_{4}$ & -0.3913 & -0.3224 & 0.0546 & 0.0000 & -0.4480 \\
\hline$\pi_{5}$ & 0.0354 & 0.0505 & 0.0910 & 0.0728 & 0.0000 \\
\hline
\end{tabular}

Table 20. The dominance degree of supplier $\pi_{x}$ over supplier $\pi_{y}$ concerning the CSF $\kappa^{\prime}{ }_{14}$

\begin{tabular}{|c|c|c|c|c|c|}
\hline$\kappa^{\prime}{ }_{14}$ & $\pi_{1}$ & $\pi_{2}$ & $\pi_{3}$ & $\pi_{4}$ & $\pi_{5}$ \\
\hline$\pi_{1}$ & 0.0000 & -0.6507 & -0.6507 & -0.7079 & 0.0430 \\
\hline$\pi_{2}$ & 0.1168 & 0.0000 & 0.0000 & -0.2789 & 0.1087 \\
\hline$\pi_{3}$ & 0.1168 & 0.0000 & 0.0000 & -0.2789 & 0.1087 \\
\hline$\pi_{4}$ & 0.1271 & 0.0501 & 0.0501 & 0.0000 & 0.1196 \\
\hline$\pi_{5}$ & -0.2393 & -0.6051 & -0.6051 & -0.6663 & 0.0000 \\
\hline
\end{tabular}

Step 5. Generate the overall dominance matrix $\varphi^{\prime}\left(\pi_{x}, \pi_{y}\right)$. Integrate dominance degree of supplier $\pi_{x}$ over supplier $\pi_{y}$ considering all CSFs, by using Eq. (18). This determines the overall dominance matrix of the suppliers $\pi_{x}(x=1,2, \ldots, 5)$ over suppliers $\pi_{y}(y=1,2, \ldots, 5)$. Table 21 presents these results. 
Table 21. The overall dominance degree of supplier $\pi_{x}$ over supplier $\pi_{y}$

\begin{tabular}{|c|c|c|c|c|c|}
\hline & $\pi_{1}$ & $\pi_{2}$ & $\pi_{3}$ & $\pi_{4}$ & $\pi_{5}$ \\
\hline$\pi_{1}$ & 0.0000 & -0.4840 & -0.6869 & -0.2201 & -0.2554 \\
\hline$\pi_{2}$ & -2.1997 & 0.0000 & -0.8456 & -1.3603 & -2.7702 \\
\hline$\pi_{3}$ & -1.9350 & -1.1939 & 0.0000 & -1.4619 & -1.5703 \\
\hline$\pi_{4}$ & -1.9203 & -0.9792 & -0.5088 & 0.0000 & -1.9461 \\
\hline$\pi_{5}$ & -1.4850 & -0.1309 & -1.4826 & -0.7999 & 0.0000 \\
\hline
\end{tabular}

Table 21 shows that all the overall dominance degrees are less than zero. This shows the poor performance of each sustainable supplier compared to other sustainable suppliers under CSFs.

Step 6. Determine the overall values $\Phi\left(\pi_{x}\right)(x=1,2 \ldots, 5)$. Next, we apply Eq. (19) to transform the overall dominance degree (Table 21) into the overall values of each supplier $\pi_{x}(x=1,2, \ldots, 5)$ under 6 CSFs. Table 22 shows the results.

Table 22. The overall values of each supplier

\begin{tabular}{|c|c|c|c|c|c|}
\hline Supplier & $\pi_{1}$ & $\pi_{2}$ & $\pi_{3}$ & $\pi_{4}$ & $\pi_{5}$ \\
\hline$\Phi\left(\pi_{x}\right)$ & 1.0000 & 0.0000 & 0.1835 & 0.3294 & 0.5927 \\
\hline
\end{tabular}

Finally, we rank all the case study suppliers as $\pi_{1} \succ \pi_{5} \succ \pi_{4} \succ \pi_{3} \succ \pi_{2}$. Sustainable supplier $\pi_{1}$ performs the best; the second-best sustainable supplier is $\pi_{5}$, followed by $\pi_{4}, \pi_{3}$ and $\pi_{2}$. The overall values of sustainable suppliers $\pi_{1}$ and $\pi_{5}$ exceed 0.4 . This indicates that these two sustainable suppliers are ranked higher than the others. There is a large gap between other suppliers and the suppliers $\pi_{1}$ and $\pi_{5}$. Supplier $\pi_{4}$ is ranked third, and $\pi_{3}$ exhibits a smaller gap with the supplier $\pi_{4}$. Suppliers $\pi_{4}, \pi_{3}$ and $\pi_{2}$ have lower rankings.

Although each supplier has different levels of dominance and overall value, the overall level of sustainable development of potential suppliers is relatively low calculated by the proposed decision-making framework. From the perspective of social credit aspects, there is a tendency that enterprises pay more attention to social performance especially credit. So the outlook related to the sustainable development of suppliers is optimistic for China.

\section{Discussions}

In this section, we change values of parameters $\zeta$ and $\mu$ to observe the ranking results. Then we make comparative analysis including the decision-making framework without identifying CSFs and the decision-making framework with TOPSIS method.

\subsection{Sensitivity analysis}

The study proposes a new decision-making framework integrating DEMATEL as well as TODIM method based on PLTSs to make SSS under 6 CSFs. There exist parameter $\zeta$ and attenuation factor of the loss $\mu$ in Eq. (17) for calculating the dominance degree. Therefore, 
it is necessary to analyze the influence of different values of parameters on the whole decision result.

In the calculation process, we set the value of $\zeta$ as 0.1 . For verifying this method, we assign different values of $0.1,0.01$, and 0.001 to $\zeta$ to assess whether the supplier ranking changes. Table 23 shows that the ranking result of suppliers is consistently $\pi_{1} \succ \pi_{5} \succ \pi_{4} \succ$ $\pi_{3} \succ \pi_{2}$ corresponding to different values of $\zeta$, and the best supplier are always $\pi_{1}$. Similarly, we assign different values to the parameter $\mu$, such as 1,2 and 3. Also, the supplier ranking remain unchanged when the value of $\mu$ changes.

From the analysis (Tables 23 and 24), the ranking results of potential sustainable suppliers are not sensitive to the changes of parameters. This displays that the parameters $\zeta$ and $\mu$ are without loss of generality, and the values we assign to the two parameters also remain generality. This indicates the robustness as well as the validity of our proposed framework.

Table 23. The sorting results for different values of $\zeta$

\begin{tabular}{|c|c|}
\hline$\zeta$ & Sorting \\
\hline 0.1 & $\pi_{1} \succ \pi_{5} \succ \pi_{4} \succ \pi_{3} \succ \pi_{2}$ \\
\hline 0.01 & $\pi_{1} \succ \pi_{5} \succ \pi_{4} \succ \pi_{3} \succ \pi_{2}$ \\
\hline 0.001 & $\pi_{1} \succ \pi_{5} \succ \pi_{4} \succ \pi_{3} \succ \pi_{2}$ \\
\hline
\end{tabular}

Table 24. The sorting results for different values of $\mu(\mu>0)$

\begin{tabular}{|c|c|}
\hline$\mu$ & Sorting \\
\hline 1 & $\pi_{1} \succ \pi_{5} \succ \pi_{4} \succ \pi_{3} \succ \pi_{2}$ \\
\hline 2 & $\pi_{1} \succ \pi_{5} \succ \pi_{4} \succ \pi_{3} \succ \pi_{2}$ \\
\hline 3 & $\pi_{1} \succ \pi_{5} \succ \pi_{4} \succ \pi_{3} \succ \pi_{2}$ \\
\hline
\end{tabular}

\subsection{Comparative analysis}

In this section, we conduct comparative analysis including decision-making framework without identifying CSFs as well as decision-making framework with TOPSIS method for verifying our framework's conciseness and effectiveness.

\subsubsection{Decision-making framework without identifying CSFs}

To verify the effectiveness and conciseness of the decision-making framework, we collect the evaluation of five potential suppliers under 15 factors. Then we transform the evaluation in the form of linguistic term into matrices of PLTSs and normalize them. In order to obtain 15 factors' weights, we calculate the factors' casual degree $E_{i}$, which stands for the influence between factors and factor systems. And we adopt $V_{i j}=\left|E_{i}\right| / \sum_{i=1}^{n}\left|E_{i}\right|$ to make all factors have positive casual degree for better reflecting the variation of factors. Next, the initial weights of 15 factors are obtained by combining entropy weight method and DEMATEL methods on the basis of PLTSs. Finally, the new dominance degree is calculated based on standard relative importance degree, and then the potential supplier is ranked. The results are shown in the Tables 25 and 26. 
Table 25. The overall dominance degree of supplier $\pi_{x}$ over supplier $\pi_{y}$ under 15 factors

\begin{tabular}{|c|c|c|c|c|c|}
\hline Supplier & $\pi_{1}$ & $\pi_{2}$ & $\pi_{3}$ & $\pi_{4}$ & $\pi_{5}$ \\
\hline$\pi_{1}$ & 0.0000 & -1.5538 & -0.0079 & -1.0410 & -1.4366 \\
\hline$\pi_{2}$ & -14.9799 & 0.0000 & -6.0382 & -5.9552 & -14.0438 \\
\hline$\pi_{3}$ & -13.4783 & -3.8533 & 0.0000 & -6.1121 & -9.9524 \\
\hline$\pi_{4}$ & -13.3861 & -1.9817 & -5.4436 & 0.0000 & -11.3529 \\
\hline$\pi_{5}$ & -6.6670 & -0.5130 & -4.4296 & -1.5723 & 0.0000 \\
\hline
\end{tabular}

Table 26. The overall values of each supplier considering 15 factors

\begin{tabular}{|c|c|c|c|c|c|}
\hline Supplier & $\pi_{1}$ & $\pi_{2}$ & $\pi_{3}$ & $\pi_{4}$ & $\pi_{5}$ \\
\hline$\Phi\left(\pi_{x}\right)$ & 1.0000 & 0.0000 & 0.2061 & 0.2394 & 0.7528 \\
\hline
\end{tabular}

As can be seen from Table 26, the ranking result of potential suppliers in the framework without identifying CSFs is: $\pi_{1} \succ \pi_{5} \succ \pi_{4} \succ \pi_{3} \succ \pi_{2}$. This calculated result under more factors is similar with our proposed decision-making framework. Thus it verifies that our decision-making framework for identifying CSFs with DEMATEL is much simpler because fewer factors are used but the same decision results are obtained. Therefore, the framework we proposed in this paper is concise while ensuring accuracy.

\subsubsection{Decision-making framework with TOPSIS method}

TOPSIS method is commonly used in practical decision making and it has also integrated with the PLTSs. As a MADM method, we select the TOPSIS method to for constructing the other framework to make comparative analysis in this section.

According to the above decision-making framework, we construct another framework consisted of DEMATEL and TOPSIS methods to make SSS for NEV Company. Probabilistic linguistic evaluations of five alternative suppliers under identified CSFs are adopted. Then, we calculate the initial standard relative degree $(S I(L(p))$ for each alternative supplier using Eq. (5) (Table 27). In line with Table 27, we obtain the maximum max $S I(L(p))$ and minimum mix $S I(L(p))$ for each CSF.

Table 27. Standard relative degree of importance $S I(L(p))$ of each sustainable supplier

\begin{tabular}{|c|c|c|c|c|c|}
\hline$S I(L(p))$ & $\pi_{1}$ & $\pi_{2}$ & $\pi_{3}$ & $\pi_{4}$ & $\pi_{5}$ \\
\hline$\kappa_{1}^{\prime}$ & 0.2722 & 0.3333 & 0.3220 & 0.2854 & 0.2434 \\
\hline$\kappa^{\prime}{ }_{4}$ & 0.2434 & 0.1377 & 0.2434 & 0.2277 & 0.2582 \\
\hline$\kappa^{\prime}{ }_{7}$ & 0.2854 & 0.2357 & 0.0974 & 0.1721 & 0.2722 \\
\hline$\kappa_{9}^{\prime}$ & 0.2177 & 0.2434 & 0.2434 & 0.2277 & 0.2854 \\
\hline$\kappa_{12}^{\prime}$ & 0.1822 & 0.2582 & 0.2582 & 0.2722 & 0.1925 \\
\hline$\kappa_{14}^{\prime}$ & 0.2357 & 0.2277 & 0.1925 & 0.2108 & 0.2434 \\
\hline
\end{tabular}


Table 28. The maximum max $S I(L(p))$ and minimum min $S I(L(p))$ of each supplier

\begin{tabular}{|l|c|c|c|c|c|}
\hline & $\pi_{1}$ & $\pi_{2}$ & $\pi_{3}$ & $\pi_{4}$ & $\pi_{5}$ \\
\hline $\max S I(L(p))$ & 0.2854 & 0.3333 & 0.3220 & 0.2854 & 0.2854 \\
\hline $\min S I(L(p))$ & 0.1822 & 0.1377 & 0.0974 & 0.1721 & 0.1925 \\
\hline
\end{tabular}

After generating Tables 27 and 28, we propose the new degree of deviation between the $S I(L(p))$ of sustainable supplier $\pi_{r}(r=1,2, \ldots, 5)$ and $\max S I(L(p))$ :

$$
\begin{gathered}
\Delta\left(\pi_{r}, \max S I(L(p))\right)=\sum_{\lambda=1,2,4,9,10} w_{\lambda} \Delta(S I(L(p)), \max S I(L(p)))= \\
\sum_{\lambda=1,2,4,9,10} w_{\lambda}\left(\sqrt{\frac{(\max S I(L(p))-S I(L(p)))^{2}}{\# L(p)}}\right)^{3},
\end{gathered}
$$

$\# L(p)$ is the number of a probabilistic linguistic terms in the NPLTSs matrix.

Similarly, the degree of deviation in the $S I(L(p))$ of sustainable supplier $\pi_{r}(r=1,2, \ldots, 5)$ and the $\min S I(L(p))$ is defined as:

$$
\begin{gathered}
\Delta\left(\pi_{\mathrm{r}}, \min S I(L(p))\right)=\sum_{\lambda=1,2,4,9,10} w_{\lambda} \Delta(S I(L(p)), \min S I(L(p)))= \\
\sum_{\lambda=1,2,4,9,10} w_{\lambda}\left(\sqrt{\frac{(S I(L(p))-\min S I(L(p)))^{2}}{\# L(p)}}\right)^{3} .
\end{gathered}
$$

Furthermore, according to Pang et al. (2016), the closeness coefficient of each sustainable supplier in this paper is described as:

$$
C\left(\pi_{r}\right)=\frac{\Delta\left(\pi_{r}, \min S I(L(p))\right)}{\max \Delta\left(\pi_{r}, \min S I(L(p))\right)}-\frac{\Delta\left(\pi_{r}, \max S I(L(p))\right)}{\min \Delta\left(\pi_{r}, \max S I(L(p))\right)},
$$

where $C\left(\pi_{r}\right) \leq 0(r=1,2, \ldots, 5), \max \Delta\left(o_{r}, \max S I(L(p))\right)$ is the biggest degree of deviation between the sustainable supplier $\pi_{r}$ and $\max S I(L(p))$, and $\max \left(\pi_{r}, \max S I(L(p))\right)=\max _{1 \leq r \leq 5} \Delta\left(\pi_{r}, \min \right.$ $S I(L(p))$. The term $\min \Delta\left(\pi_{r}, \max S I(L(p))\right)$ represents the smallest degree of deviation between the sustainable supplier $\pi_{r}$ and $\max S I(L(p))$, and $\min \left(\pi_{r}, \max S I(L(p))\right)=\min _{1 \leq r \leq 5} \Delta\left(\pi_{r}, \max \right.$ $S I(L(p))$.

Finally, we rank the five suppliers according to the calculated closeness coefficient $C\left(\pi_{r}\right)$ according to Table 29. We generate a new ranking of the sustainable performance of the 5 NEVs suppliers: $\pi_{1} \succ \pi_{3} \succ \pi_{5} \succ \pi_{4} \succ \pi_{2}$.

Table 29. Closeness coefficients

\begin{tabular}{|c|c|c|c|}
\hline$\left.\Delta\left(\pi_{r}, \min S I\right)(L(p))\right)$ & $\left.\Delta\left(\pi_{r}, \max S I\right)(L(p))\right)$ & $C\left(\pi_{r}\right)$ & Ranking \\
\hline 0.00026 & 0.00004 & -0.02903 & 3 \\
\hline 0.00011 & 0.00006 & -1.14143 & 5 \\
\hline 0.00005 & 0.00023 & -5.67167 & 4 \\
\hline 0.00004 & 0.00006 & -1.39054 & 2 \\
\hline 0.00024 & 0.00004 & -0.05562 & \\
\hline
\end{tabular}


From the ranking results of two methods, the comparison reveals that the optimal sustainable supplier is $\pi_{1}$ and the worst is $\pi_{2}$, which the same outcomes are as the result obtained using the preamble framework. This indicates the validity of the proposed decision-making framework. However, there are differences in the ranking of suppliers $\pi_{3}, \pi_{4}$ and $\pi_{5}$. Supplier $\pi_{3}$ performs worse than $\pi_{4}, \pi_{5}$ using the proposed framework. In contrast, $\pi_{3}$ performs better than $\pi_{4}, \pi_{5}$. using the comparative framework. In order to further explain the rationality of the proposed framework, we introduce the concept of score function $E(L(p))=\sum_{k=1}^{\# L(\mathrm{p})} r^{(k)} p^{(k)} / \sum_{k=1}^{\# L(p)} p^{(k)}$ (Pang et al., 2016), which is used to compare PLTSs with each other. Take supplier $\pi_{3}, \pi_{5}$ for example, according to Table 13 , we get the sum score value of supplier $\pi_{3} \sum E(L(p))=[(0 \cdot 2+2 \cdot 0.2+3 \cdot 0.8)+(0 \cdot 0+0 \cdot 0.2+2 \cdot 0.8)$ $+(0 \cdot 0.2+1 \cdot 0.6+2 \cdot 0.2)+((-3) \cdot 0.2+(-2) \cdot 0.6+0 \cdot 0.2)] / 1+[(0 \cdot 0.6+0 \cdot 2+2 \cdot 0.2)+$ $((-1) 0.2+2 \cdot 0.4+3 \cdot 0.2)] / 0.8=5.2$, and the sum score value of supplier $\pi_{3} \sum E(L(p))=$ $[(0 \cdot 1+0.4 \cdot 1+2 \cdot 0.6)+((-1) \cdot 0.4+2 \cdot 0.4+3 \cdot 0.2)+((-3) \cdot 0.2+1 \cdot 0.2+2 \cdot 0.6)+$ $((-2) \cdot 0.2+0 \cdot 0.2+3 \cdot 0.6)+(1 \cdot 0.6+2 \cdot 0.2+3 \cdot 0.2)+((-1) \cdot 0.6+0 \cdot 0.2+2 \cdot 0.2] / 1=5.8$. Apparently, the experts' evaluation of supplier $\pi_{5}$ is better than supplier $\pi_{3}$. It proves that the proposed decision-making framework composed of TODIM method is more effective than the framework with TOPSIS method for SSS. The main reason for this difference is that the TOPSIS approach does not consider the influence of experts' psychology.

\section{Conclusions}

The suitable sustainable supplier helps enterprise realize healthy and steady development. This paper proposes a new decision-making framework for SSS. Firstly, we reconstruct a new factor system considering social credit under the circumstance that the Chinese government intensifying efforts to build a national credit system. Secondly, this paper innovatively proposes the relative importance degree, standard relative importance degree, deviation of importance degree, and influence degree to measure the interactive influence between factors based on PLTSs. Then we combine PLTS and DEMATEL to identify the CSFs. Thirdly, we combine entropy weighting method with DEMATEL method to compute CSFs' weights. Fourthly, we adopt TODIM method to combine with PLTS, DEMATEL, and entropy weighting method for constructing the new decision-making framework. Also, the case study of a NEV company is applied to make numerical calculation. Finally, sensitivity analysis and comparative analysis are conducted. In comparative analysis, we not only make comparison with decision-making framework without identifying CSFs, but also the decision-making framework with TOPSIS method. The analysis verifies the stability and effectiveness of the proposed decision-making framework.

In the future, we will try to construct a more detailed factor system for enterprises to refer, such as the more detailed perspectives and the more detailed analysis of social status. Combining with text mining, the problem of large-scale group decision-making in sustainable supplier selection with expert consensus is the content of our future research. In terms of the decision-making framework, we design and implement it from the perspective of the enterprise's choice of sustainable suppliers, and the subsequent research should explore its contribution to the overall sustainable development in reality. 


\section{Funding}

Our work is sponsored by the National Natural Science Foundation of China (Grant Nos. 71701116, 71871034 and 71901044), China Postdoctoral Science Foundation (2020M673271), Humanities and Social Science Fund of Ministry of Education of China (Grant Nos. 15YJC630016 and 18YJC630009), Scientific and Technological Innovation Programs of Higher Education Institutions in Shanxi (Grant No. 2019L0484) and the Key Research and Development Project of Shanxi Province (201903D121160).

\section{Author contributions}

Yuanxiang Dong and Xumei Zheng conceived the study and were responsible for the design and development of the data analysis. Weijie Chen, Hongbo Shi, and Ke Gong were responsible for data collection and analysis. Xumei Zheng wrote the first draft of the article. Yuanxiang Dong, Weijie Chen as well as Ke Gong was responsible for supervision and funding acquisition. Zeshui Xu confirmed the content of the entire research design.

\section{Disclosure statement}

The authors declare that there is no conflict of interest regarding the publication of this paper.

\section{References}

Ahi, P., \& Searcy, C. (2013). A comparative literature analysis of definitions for green and sustainable supply chain management. Journal of Cleaner Production, 52, 329-341.

https://doi.org/10.1016/j.jclepro.2013.02.018

Amindoust, A., Ahmed, S., Saghafinia, A., \& Bahreininejad, A. (2012). Sustainable supplier selection: A ranking model based on fuzzy inference system. Applied Soft Computing, 12(6), 1668-1677. https://doi.org/10.1016/j.asoc.2012.01.023

Bai, C., \& Sarkis, J. (2010). Integrating sustainability into supplier selection with grey system and rough set methodologies. International Journal of Production Economics, 124, 252-264. https://doi.org/10.1016/j.ijpe.2009.11.023

Banaeian, N., Mobli, H., Fahimnia, B., Nielsen, I. E., \& Omid, M. (2018). Green supplier selection using fuzzy group decision making methods: A case study from the agri-food industry. Computers \& Operations Research, 89, 337-347. https://doi.org/10.1016/j.cor.2016.02.015

Blome, C., Hollos, D., \& Paulraj, A. (2014). Green procurement and green supplier development: antecedents and effects on supplier performance. International Journal of Production Research, 52(1), 32-49. https://doi.org/10.1080/00207543.2013.825748

Boudaghi, E., \& Farzipoor Saen, R. (2018). Developing a novel model of data envelopment analysisdiscriminant analysis for predicting group membership of suppliers in sustainable supply chain. Computers \& Operations Research, 89, 348-359. https://doi.org/10.1016/j.cor.2017.01.006

Busse, C., Schleper, M. C., Niu, M., \& Wagner, S. M. (2016). Supplier development for sustainability: contextual barriers in global supply chains. International Journal of Physical Distribution \& Logistics Management, 46(5), 442-468. https://doi.org/10.1108/IJPDLM-12-2015-0300

Chaharsooghi, S. K., \& Ashrafi, M. (2014). Sustainable supplier performance evaluation and selection with neofuzzy TOPSIS method. International Scholarly Research Notices, 2014, 434168.

https://doi.org/10.1155/2014/434168 
Chen, Y. J. (2011). Structured methodology for supplier selection and evaluation in a supply chain. Information Sciences, 181(9), 16511670. https://doi.org/10.1016/j.ins.2010.07.026

Chen, Y. T., Chen, C. H., Wu, S., \& Lo, C. C. (2018). A two-step approach for classifying music genre on the strength of AHP weighted musical features. Mathematics, 7(1), 19. https://doi.org/10.3390/math7010019

China Environmental Protection Industry Association. (2018). Environmental protection enterprise credit evaluation index system (T/CAEPI 15-2018). https://www.uedoc.com/view/15606328.html

Chinese State Council. (2014). The development plan for the industry of energy-efficient vehicle and new energy vehicle (2011-2020). http://www.nea.gov.cn/2012-07/10/c_131705726.htm

Cuthbertson, R., Cetinkaya, B., Ewer, G., Klaas-Wissing, T., Piotrowicz, W., \& Tyssen, C. (2011). Sustainable supply chain management. Springer. https://doi.org/10.1007/978-3-642-12023-7

Daultani, Y., Goswami, M., Vaidya, O. S., \& Kumar, S. (2019). Inclusive risk modeling for manufacturing firms: a Bayesian network approach. Journal of Intelligent Manufacturing, 30(8), 2789-2803. https://doi.org/10.1007/s10845-017-1374-7

Elkington, J. (1998). Partnerships from cannibals with forks: The triple bottom line of 21st-century business. Environmental Quality Management, 8(1), 37-51. https://doi.org/10.1002/tqem.3310080106

Fallahpour, A., Olugu, E. U., Musa, S. N., Wong, K. Y., \& Noori, S. (2017). A decision support model for sustainable supplier selection in sustainable supply chain management. Computers \& Industrial Engineering, 105, 391-410. https://doi.org/10.1016/j.cie.2017.01.005

Foroozesh, N., Tavakkoli-Moghaddam, R., \& Mousavi, S. M. (2018). An interval-valued fuzzy statistical group decision making approach with new evaluating indices for sustainable supplier selection problem. Journal of Intelligent \& Fuzzy Systems, 36(2), 1855-1866. https://doi.org/10.3233/JIFS-17467

Gao, J., Xu, Z. S., Ren, P. J., \& Liao, H. C. (2019). An emergency decision making method based on the multiplicative consistency of probabilistic linguistic preference relations. International Journal of Machine Learning and Cybernetics, 10(7), 1613-1629. https://doi.org/10.1007/s13042-018-0839-0

Garg, C., Sharma, A., \& Goyal, G. (2017). A hybrid decision model to evaluate critical factors for successful adoption of GSCM practices under fuzzy environment. Uncertain Supply Chain Management, 5(1), 59-70. https://doi.org/10.5267/j.uscm.2016.7.002

General Administration of Customs of the People's Republic of China. (2019). Customs statistics. http://www.customs.gov.cn/customs/302249/302274/302277/3250476/index.html

Girubha, J., Vinodh, S., \& Vimal, K. E. K. (2016). Application of interpretative structural modelling integrated multi criteria decision making methods for sustainable supplier selection. Journal of Modelling in Management, 11(2), 358-388. https://doi.org/10.1108/JM2-02-2014-0012

Gören, H. G. (2018). A decision framework for sustainable supplier selection and order allocation with lost sales. Journal of Cleaner Production, 183, 1156-1169. https://doi.org/10.1016/j.jclepro.2018.02.211

Gou, X. J., \& Xu, Z. S. (2016). Novel basic operational laws for linguistic terms, hesitant fuzzy linguistic term sets and probabilistic linguistic term sets. Information Sciences, 372, 407-427. https://doi.org/10.1016/j.ins.2016.08.034

Govindan, K., Khodaverdi, R., \& Jafarian, A. (2013). A fuzzy multi criteria approach for measuring sustainability performance of a supplier based on triple bottom line approach. Journal of Cleaner Production, 47, 345-354. https://doi.org/10.1016/j.jclepro.2012.04.014

Graham, G., Freeman, J., \& Chen, T. (2015). Green supplier selection using an AHP-Entropy-TOPSIS framework. Supply Chain Management: An International Journal, 20(3), 327-340. https://doi.org/10.1108/SCM-04-2014-0142

Haeri, S. A. S., \& Rezaei, J. (2019). A grey-based green supplier selection model for uncertain environments. Journal of Cleaner Production, 221, 768-784. https://doi.org/10.1016/j.jclepro.2019.02.193 
Hendiani, S., Liao, H., Ren, R., \& Lev, B. (2020). A likelihood-based multi-criteria sustainable supplier selection approach with complex preference information. Information Sciences, 536, 135-155. https://doi.org/10.1016/j.ins.2020.05.065

Hoseini, A. R., Ghannadpour, S. F., \& Ghamari, R. (2020). Sustainable supplier selection by a new possibilistic hierarchical model in the context of Z-information. Journal of Ambient Intelligence and Humanized Computing, 11, 4827-4853. https://doi.org/10.1007/s12652-020-01751-3

Hou, J., Zhang, Q., Hu, S., \& Chen, D. (2020). Evaluation of a new extended producer responsibility mode for WEEE based on a supply chain scheme. Science of The Total Environment, 726, 138531. https://doi.org/10.1016/j.scitotenv.2020.138531

Hu, K. H., Chen, F. H., Hsu, M. F., \& Tzeng, G. H. (2021). Identifying key factors for adopting artificial intelligence-enabled auditing techniques by joint utilization of fuzzy-rough set theory and MRDM technique. Technological and Economic Development of Economy, 27(2), 459-492. https://doi.org/10.3846/tede.2020.13181

Igarashi, M., de Boer, L., \& Fet, A. M. (2013). What is required for greener supplier selection? A literature review and conceptual model development. Journal of Purchasing and Supply Management, 19(4), 247-263. https://doi.org/10.1016/j.pursup.2013.06.001

Jabbar, F. K., Grote, K., \& Tucker, R. E. (2019). A novel approach for assessing watershed susceptibility using weighted overlay and analytical hierarchy process (AHP) methodology: a case study in Eagle Creek Watershed, USA. Environmental Science and Pollution Research, 26, 31981-31997. https://doi.org/10.1007/s11356-019-06355-9

Jia, P., Govindan, K., Choi, T. M., \& Rajendran, S. (2015). Supplier selection problems in fashion business operations with sustainability considerations. Sustainability, 7(2), 1603-1619. https://doi.org/10.3390/su7021603

Kannan, D., Mina, H., Nosrati-Abarghooee, S., \& Khosrojerdi, G. (2020). Sustainable circular supplier selection: A novel hybrid approach. The Science of the Total Environment, 722, 137936-137936. https://doi.org/10.1016/j.scitotenv.2020.137936

Kaur, P. (2014). Selection of vendor based on intuitionistic fuzzy analytical hierarchy process. Advances in Operations Research, 2014, 987690. https://doi.org/10.1155/2014/987690

Khan, M. A., Mittal, S., West, S., \& Wuest, T. (2018). Review on upgradability - A product lifetime extension strategy in the context of product service systems. Journal of Cleaner Production, 204, 1154-1168. https://doi.org/10.1016/j.jclepro.2018.08.329

Khoshfetrat, S., Rahiminezhad Galankashi, M., \& Almasi, M. (2020). Sustainable supplier selection and order allocation: a fuzzy approach. Engineering Optimization, 52(9), 1494-1507. https://doi.org/10.1080/0305215X.2019.1663185

Lei, F., Lu, J., Wei, G., Wu, J., Wei, C., \& Guo, Y. (2020a). GRA method for waste incineration plants location problem with probabilistic linguistic multiple attribute group decision making. Journal of Intelligent \& Fuzzy Systems, 39(3), 2909-2920. https://doi.org/10.3233/JIFS-191443

Lei, F., Wei, G., Wu, J., Wei, C., \& Guo, Y. (2020b). QUALIFLEX method for MAGDM with probabilistic uncertain linguistic information and its application to green supplier selection. Journal of Intelligent \& Fuzzy Systems, 39(5), 6819-6831. https://doi.org/10.3233/JIFS-191737

Liao, H., Ren, R., Antucheviciene, J., Šaparauskas, J., \& Al-Barakati, A. (2020). Sustainable construction supplier selection by a multiple criteria decision-making method with hesitant linguistic information. E\&M Economics and Management, 23(4), 119-136. https://doi.org/10.15240/tul/001/2020-4-008

Lin, M., Wang, H., Xu, Z. S., Yao, Z., \& Huang, J. (2018a). Clustering algorithms based on correlation coefficients for probabilistic linguistic term sets. International Journal of Intelligent Systems, 33(12), 2402-2424. https://doi.org/10.1002/int.22040 
Lin, S., Li, C., Xu, F., Liu, D., \& Liu, J. (2018b). Risk identification and analysis for new energy power system in China based on D numbers and decision-making trial and evaluation laboratory (DEMATEL). Journal of Cleaner Production, 180, 81-96. https://doi.org/10.1016/j.jclepro.2018.01.153

Liu, A., Xiao, Y., Lu, H., Tsai, S. B., \& Song, W. (2019a). A fuzzy three-stage multi-attribute decisionmaking approach based on customer needs for sustainable supplier selection. Journal of Cleaner Production, 239, 118043. https://doi.org/10.1016/j.jclepro.2019.118043

Liu, H. C., Quan, M. Y., Li, Z., \& Wang, Z. L. (2019b). A new integrated MCDM model for sustainable supplier selection under interval-valued intuitionistic uncertain linguistic environment. Information Sciences, 486, 254-270. https://doi.org/10.1016/j.ins.2019.02.056

Liu, Z., Hao, H., Cheng, X., \& Zhao, F. (2018). Critical issues of energy efficient and new energy vehicles development in China. Energy Policy, 115, 92-97. https://doi.org/10.1016/j.enpol.2018.01.006

Liu, Z., Ming, X., \& Song, W. (2019c). A framework integrating interval-valued hesitant fuzzy DEMATEL method to capture and evaluate co-creative value propositions for smart PSS. Journal of Cleaner Production, 215, 611-625. https://doi.org/10.1016/j.jclepro.2019.01.089

Luthra, S., Govindan, K., Kannan, D., Mangla, S. K., \& Garg, C. P. (2017). An integrated framework for sustainable supplier selection and evaluation in supply chains. Journal of Cleaner Production, 140, 1686-1698. https://doi.org/10.1016/j.jclepro.2016.09.078

Memari, A., Dargi, A., Jokar, M. R. A., Ahmad, R., \& Rahim, A. R. A. (2019). Sustainable supplier selection: A multi-criteria intuitionistic fuzzy TOPSIS method. Journal of Manufacturing Systems, 50, 9-24. https://doi.org/10.1016/j.jmsy.2018.11.002

Mi, X., Liao, H. C., Liao, Y., Lin, Q., \& Al-Barakati, A. (2020). Green suppler selection by an integrated method with stochastic acceptability analysis and multimoora. Technological and Economic Development of Economy, 26(3), 549-572. https://doi.org/10.3846/tede.2020.11964

Ministry of Commerce of the People's Republic of China. (2019). The evaluation criteria for corporatesocial-responsibility of business service industry (SB/T 10963-2013). http://www.gbstandards.org/ GB_standard_english.asp?code=SB/T\%2010963-2013\&word=The $\% 20$ evaluation $\% 20$ criteria $\% 20$ for\% $20 \mathrm{co}$

National Standardization Administration of China. (2015a). Index of enterprise credit evaluation (GB/T 23794-2015). https://www.chinesestandard.net/PDF/English.aspx/GBT23794-2015

National Standardization Administration of China. (2015b). Enterprise integrity management system (GB/T 31950-2015). http://whly.gd.gov.cn/gd_zww/upload/file/file/201706/19093213dz6i.pdf

Negash, Y. T., Kartika, J., Tseng, M. L., \& Tan, K. (2020). A novel approach to measure product quality in sustainable supplier selection. Journal of Cleaner Production, 252, 119838. https://doi.org/10.1016/j.jclepro.2019.119838

Neumüller, C., Lasch, R., \& Kellner, F. (2016). Integrating sustainability into strategic supplier portfolio selection. Management Decision, 54(1), 194-221. https://doi.org/10.1108/MD-05-2015-0191

Pang, Q., Wang, H., \& Xu, Z. S. (2016). Probabilistic linguistic term sets in multi-attribute group decision making. Information Sciences, 369, 128-143. https://doi.org/10.1016/j.ins.2016.06.021

Parajuli, R., Thoma, G., \& Matlock, M. D. (2019). Environmental sustainability of fruit and vegetable production supply chains in the face of climate change: A review. Science of the Total Environment, 650, 2863-2879. https://doi.org/10.1016/j.scitotenv.2018.10.019

Peng, J. J., Tian, C., Zhang, W. Y., Zhang, S., \& Wang, J. Q. (2020). An integrated multi-criteria decisionmaking framework for sustainable supplier selection under picture fuzzy environment. Technological and Economic Development of Economy, 26(3), 1-26. https://doi.org/10.3846/tede.2020.12110

Phochanikorn, P., \& Tan, C. (2019). A new extension to a multi-criteria decision-making model for sustainable supplier selection under an intuitionistic fuzzy environment. Sustainability, 11(19), 5413. https://doi.org/10.3390/su11195413 
Rashidi, K., \& Cullinane, K. (2019). A comparison of fuzzy DEA and fuzzy TOPSIS in sustainable supplier selection: Implications for sourcing strategy. Expert Systems with Applications, 121, 266-281. https://doi.org/10.1016/j.eswa.2018.12.025

Rodriguez, R. M., Martinez, L., \& Herrera, F. (2011). Hesitant fuzzy linguistic term sets for decision making. IEEE Transactions on Fuzzy Systems, 20(1), 109-119. https://doi.org/10.1109/TFUZZ.2011.2170076

Sahu, A. K., Datta, S., \& Mahapatra, S. S. (2016). Evaluation and selection of resilient suppliers in fuzzy environment. Benchmarking: An International Journal, 23(3), 651-673. https://doi.org/10.1108/BIJ-11-2014-0109

Senvar, O., Tuzkaya, G., \& Kahraman, C. (2014). Multi criteria supplier selection using fuzzy PROMETHEE method. In Supply chain management under fuzziness (pp. 21-34). Springer. https://doi.org/10.1007/978-3-642-53939-8_2

Seuring, S., \& Müller, M. (2008). From a literature review to a conceptual framework for sustainable supply chain management. Journal of Cleaner Production, 16(15), 1699-1710. https://doi.org/10.1016/j.jclepro.2008.04.020

Song, W., Xu, Z. T., \& Liu, H. C. (2017). Developing sustainable supplier selection criteria for solar air-conditioner manufacturer: An integrated approach. Renewable and Sustainable Energy Reviews, 79, 1461-1471. https://doi.org/10.1016/j.rser.2017.05.081

Song, Y., \& Li, G. (2019). A large-scale group decision-making with incomplete multi-granular probabilistic linguistic term sets and its application in sustainable supplier selection. Journal of the OPerational Research Society, 70(5), 827-841. https://doi.org/10.1080/01605682.2018.1458017

Szegedi, K., \& Kerekes, K. N. (2012). Challenges of responsible supply chain management. Club of Economics in Miskolc, 8(2), 68-75.

The State Council. (2012). The energy-saving and new energy vehicle industry development plan (20122020) (No. Guofa [2012] 22). Beijing.

The State Council. (2014, June 27). Outline of the plan for the construction of the social credit system (2014-2020). http://www.gov.cn/xinwen/2014-06/27/content_2708964.htm

The State Council. (2017, December 1). "Five years of endeavor" in the construction of social credit system. https://www.creditchina.gov.cn/xinyongyanjiu/xinyongyanjiuhuicui/201712/t20171201_98144. html

The State Council. (2021, March 4). Green credit system. https://www.creditchina.gov.cn/xinyongyanjiu/ xinyongshalong/202103/t20210304_228711.html

Tzeng, G. H., Chiang, C. H., \& Li, C. W. (2007). Evaluating intertwined effects in e-learning programs: A novel hybrid MCDM model based on factor analysis and DEMATEL. Expert systems with Applications, 32(4), 1028-1044. https://doi.org/10.1016/j.eswa.2006.02.004

Underwriters Laboratories. (2011). Sustainability for manufacturing organizations (UL 880-2011). http://std600.infoeach.com/view-NjAwfDIwMDQ4NQ==.html

Wang, S., Wei, G., Wu, J., Wei, C., \& Guo, Y. (2021). Model for selection of hospital constructions with probabilistic linguistic GRP method. Journal of Intelligent \& Fuzzy Systems, 40(1), 1245-1259. https://doi.org/10.3233/JIFS-201543

Wang, Y., Li, L., Chen, C., Huang, C., Huang, H., Feng, J., Wang, S., Wang, H., Zhang, G., Zhou, M., Cheng, P., Wu, M., Sheng, G., Fu, J., Hu, Y., Russell, A. G., \& Wumaer, A. (2014). Source apportionment of fine particulate matter during autumn haze episodes in Shanghai, China. Journal of Geophysical Research: Atmospheres, 119(4), 1903-1914. https://doi.org/10.1002/2013JD019630

Wei, C., Wu, J., \& Guo, Y., \& Wei, G. (2021a). Green supplier selection based on CODAS method in probabilistic uncertain linguistic environment. Technological and Economic Development of Economy, 27(3), 530-549. https://doi.org/10.3846/tede.2021.14078 
Wei, G., Wei, C., Wu, J., \& Guo, Y. (2021b). Probabilistic linguistic multiple attribute group decision making for location planning of electric vehicle charging stations based on the generalized Dice similarity measures. Artificial Intelligence Review, 54, 4137-4167. https://doi.org/10.1007/s10462-020-09950-2

Wei, G., Wei, C., Wu, J., \& Wang, H. (2019). Supplier selection of medical consumption products with a probabilistic linguistic MABAC method. International Journal of Environmental Research and Public Health, 16(24), 5082. https://doi.org/10.3390/ijerph16245082

Wilson, E. J. (1994). The relative importance of supplier selection criteria: a review and update. International Journal of Purchasing and Materials Management, 30(2), 34-41. https://doi.org/10.1111/j.1745-493X.1994.tb00195.x

Wisner, J. D., Tan, K.-C., \& Leong, G. K. (2014). Principles of supply chain management: A balanced approach. Cengage Learning.

Wittstruck, D., \& Teuteberg, F. (2012). Integrating the concept of sustainability into the partner selection process: a fuzzy-AHP-TOPSIS approach. International Journal of Logistics Systems and Management, 12(2), 195-226. https://doi.org/10.1504/IJLSM.2012.047221

Wu, H.-H., \& Chang, S.-Y. (2015). A case study of using DEMATEL method to identify critical factors in green supply chain management. Applied Mathematics and Computation, 256, 394-403. https://doi.org/10.1016/j.amc.2015.01.041

Wu, Y., Ke, Y., Xu, C., \& Li, L. (2019). An integrated decision-making model for sustainable photovoltaic module supplier selection based on combined weight and cumulative prospect theory. Energy, 181, 1235-1251. https://doi.org/10.1016/j.energy.2019.06.027

Xu, Z. S. (2007). Multiple-attribute group decision making with different formats of preference information on attributes. IEEE Transactions on Systems, Man, \& Cybernetics, Part B, 37(6), 1500-1511. https://doi.org/10.1109/TSMCB.2007.904832

Xu, Z. S. (2012). Linguistic decision making. Springer. https://doi.org/10.1007/978-3-642-29440-2

Xu, Z. S., \& Wang, H. (2017). On the syntax and semantics of virtual linguistic terms for information fusion in decision making. Information Fusion, 34, 43-48. https://doi.org/10.1016/j.inffus.2016.06.002

Yu, C., Shao, Y., Wang, K., \& Zhang, L. (2019). A Group decision making sustainable supplier selection approach using extended TOPSIS under interval-valued Pythagorean fuzzy environment. Expert Systems with Applications, 121, 1-17. https://doi.org/10.1016/j.eswa.2018.12.010

Yu, W., Zhang, Z., Zhong, Q., \& Sun, L. (2017). Extended TODIM for multi-criteria group decision making based on unbalanced hesitant fuzzy linguistic term sets. Computers \& Industrial Engineering, 114, 316-328. https://doi.org/10.1016/j.cie.2017.10.029

Zhang, X., \& Bai, X. (2017). Incentive policies from 2006 to 2016 and new energy vehicle adoption in 2010-2020 in China. Renewable and Sustainable Energy Reviews, 70, 24-43. https://doi.org/10.1016/j.rser.2016.11.211

Zhang, Y. X., Xu, Z. S., \& Liao, H. C. (2017). A consensus process for group decision making with probabilistic linguistic preference relations. Information Sciences, 414, 260-275.

https://doi.org/10.1016/j.ins.2017.06.006

Zhang, Y. X., Xu, Z. S., \& Liao, H. C. (2019). Water security evaluation based on the TODIM method with probabilistic linguistic term sets. Soft Computing, 23(15), 6215-6230. https://doi.org/10.1007/s00500-018-3276-9

Zhou, X. Y., \& Xu, Z. D. (2018). An integrated sustainable supplier selection approach based on hybrid information aggregation. Sustainability, 10(7), 2543. https://doi.org/10.3390/su10072543

Zimmer, K., Fröhling, M., \& Schultmann, F. (2016). Sustainable supplier management - a review of models supporting sustainable supplier selection, monitoring and development. International Journal of Production Research, 54(5), 1412-1442. https://doi.org/10.1080/00207543.2015.1079340 